\title{
Raman Spectra of $\mathrm{ZrS}_{2}$ and $\mathrm{ZrSe}_{2}$ from Bulk to Atomically Thin Layers
}

\author{
Samuel Mañas-Valero, Víctor García-López, Andrés Cantarero and Marta Galbiati * \\ Instituto de Ciencia Molecular (ICMol), Universidad de Valencia, Catedrático José Beltrán 2, 46980 Paterna, \\ Spain; samuel.manas@uv.es (S.M.-V.); garlovic@alumni.uv.es (V.G.-L.); andres.cantarero@uv.es (A.C.) \\ * Correspondence: marta.galbiati@uv.es; Tel.: +34-9635-44415 \\ Academic Editor: Andres Castellanos-Gomez \\ Received: 30 July 2016; Accepted: 8 September 2016; Published: 15 September 2016
}

\begin{abstract}
In the race towards two-dimensional electronic and optoelectronic devices, semiconducting transition metal dichalcogenides (TMDCs) from group VIB have been intensively studied in recent years due to the indirect to direct band-gap transition from bulk to the monolayer. However, new materials still need to be explored. For example, semiconducting TMDCs from group IVB have been predicted to have larger mobilities than their counterparts from group VIB in the monolayer limit. In this work we report the mechanical exfoliation of $\mathrm{ZrX}_{2}(X=S$, Se) from bulk down to the monolayer and we study the dimensionality dependence of the Raman spectra in ambient conditions. We observe Raman signal from bulk to few layers and no shift in the peak positions is found when decreasing the dimensionality. While a Raman signal can be observed from bulk to a bilayer for $\mathrm{ZrS}_{2}$, we could only detect signal down to five layers for flakes of $\mathrm{ZrSe}_{2}$. These results show the possibility of obtaining atomically thin layers of $\mathrm{ZrX}_{2}$ by mechanical exfoliation and represent one of the first steps towards the investigation of the properties of these materials, still unexplored in the two-dimensional limit.
\end{abstract}

Keywords: transition metal dichalcogenides; 2D materials; Raman spectroscopy; exfoliation; Atomically-thin layers; semiconductors

\section{Introduction}

Layered transition metal dichalcogenides (TMDCs) have recently attracted strong interest in the scientific community due to the new properties that may arise from the two-dimensional (2D) limit and their possible dependence on the number of layers [1]. Layered TMDCs are formed by the weak stacking of $\mathrm{X}-\mathrm{M}-\mathrm{X}$ sandwiches (where $\mathrm{M}$ is a transition metal and $\mathrm{X}$ is a chalcogen atom; see Figure 1 ). In this structure, the out-of-plane bonding (van der Waals forces) is much weaker than the in-plane one (covalent bonding), making these materials ideal for the isolation of thin layers and the study of dimensionality effects [2].

The archetypal example of properties dependence on dimensionality is graphene. In bulk (i.e., graphite), the motion of the charge carriers is described by the Schrödinger equation, whereas in the monolayer limit it is given by the Dirac equation [3]. However, the absence of a band gap in graphene makes it unsuitable for the realization of devices such as field effect transistors (FETs). In order to overcome this problem and complement graphene, semiconducting layered TMDCs of the group VIB (Mo, W) have acquired a relevant role [4]. Indeed, these materials present remarkable layer-dependent properties in the transition from an indirect band-gap (bulk) to a direct one (monolayer). Thus, with these 2D materials and their combination in heterostructures, it is possible to fabricate new electronic and optoelectronic devices such as flexible FETs, high-electron-mobility transistors (HEMTs), p-n junctions, alternative thin-film solar cells, or photodetectors, among others [5]. 
Nevertheless, despite their strong potential, to date most of the layered TMDCs remain almost or completely unexplored. For instance, recent experiments on TMDCs from group VB ( $\mathrm{Nb}, \mathrm{Ta})$, which show metallic/superconductor behavior, have revealed opposite tendencies when approaching the 2D limit: a superconducting critical temperature $\left(T_{\mathrm{c}}\right)$ suppression in $2 \mathrm{H}-\mathrm{NbSe}_{2}[6-8]$ and a $T_{\mathrm{c}}$ enhancement in $2 \mathrm{H}-\mathrm{TaS}_{2}[9]$.

So far, the semiconducting TMDCs from group IVB (Ti, $\mathrm{Zr}, \mathrm{Hf}$ ) have not been investigated as much as their counterparts from group VIB. Recently, many-body states have been tuned in a monolayer of TiSe $_{2}$ [10] and, regarding HfX $2\left(X=S\right.$, Se), thin films of $\mathrm{HfS}_{2}[11,12]$ and $\mathrm{HfSe}_{2}$ [13] have been studied for their potential applications in FETs and phototransistors since it is theoretically predicted that monolayers of $\mathrm{Zr}$ and Hf TMDCs may exhibit higher mobility than group VIB ones [14]. In addition to the predicted higher mobility, it has been theoretically foretold that $\mathrm{ZrX} \mathrm{X}_{2}$ monolayer may also exhibit an indirect-to-direct band gap transition tuned by strain $[15,16]$ and even a semiconductor-to-metal phase transition [17].

However, to the best of our knowledge, mechanically exfoliated thin layers of $\mathrm{ZrX} \mathrm{X}_{2}$ have not been reported yet. There are few studies on thin layers of $\mathrm{ZrX}_{2}$ and they are obtained by chemical exfoliation (nanosheets and nanodiscs) $[18,19]$, or grown by chemical vapor deposition (nanobelts and flakes) [20-22] or epitaxy [23].

Nowadays, Raman spectroscopy is a common and useful technique in the characterization of 2D materials [24] since the composition [25], polytypism [26], number of layers [27], strain [28], and the existence of defects [29] can be detected. $\mathrm{ZrX}_{2}$ TMDCs present a $1 \mathrm{~T}$ structure (i.e., one atom of zirconium is octahedrally coordinated by six atoms of chalcogen), as shown in Figure 1a,b, where a lateral view of a unit cell and the top view of four unit cells are represented, respectively. The structure is a trigonal crystal system with a P-3m1 space group and the unit cell is determined by $\alpha=\beta=90^{\circ}$, $\gamma=120^{\circ}$, and $\mathrm{a}=\mathrm{b}=3.663(2) \AA, \mathrm{c}=5.827(6) \AA$ for $\mathrm{ZrS}_{2}$ and $\mathrm{a}=\mathrm{b}=3.772(2) \AA, \mathrm{c}=6.125(5) \AA$ for $\mathrm{ZrSe}_{2}$ [30]. The Raman spectrum of bulk compounds consists of the $\mathrm{E}_{\mathrm{g}}$ mode $\left(250.0 \mathrm{~cm}^{-1}\right)$ and the $\mathrm{A}_{1 \mathrm{~g}}$ mode $\left(334.1 \mathrm{~cm}^{-1}\right)$ for $\mathrm{ZrS}_{2}$, and the $\mathrm{E}_{\mathrm{g}}$ mode $\left(145.5 \mathrm{~cm}^{-1}\right)$ and the $\mathrm{A}_{1 \mathrm{~g}}$ mode $\left(194.5 \mathrm{~cm}^{-1}\right)$ for $\mathrm{ZrSe}_{2}$ [31]. Raman modes are sketched in Figure 1c.

In this work we report mechanically exfoliated thin films of $\mathrm{ZrX}_{2}$. We identify them by optical contrast and atomic force microscopy (AFM) and we study the dimensionality fingerprint in the Raman spectrum under ambient conditions.

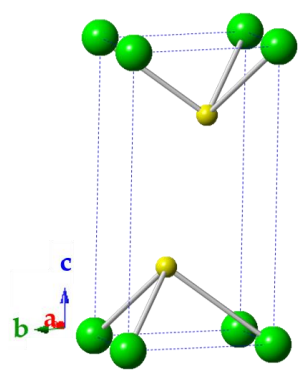

(a)

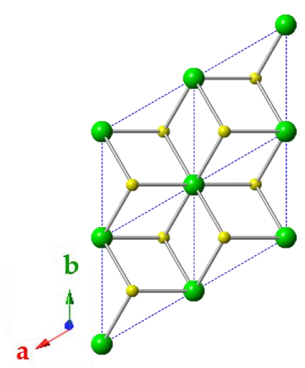

(b)

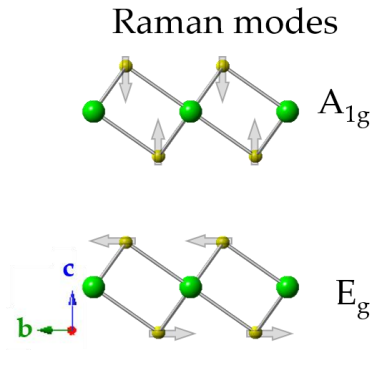

(c)

Figure 1. Representation of the crystal structure of $\mathrm{ZrX}_{2}$. Chalcogen atoms are represented in yellow and zirconium atoms in green. (a) Lateral view of a unit cell; (b) c-axis view of four unit cells; (c) extended view of the crystal structure where the layered structure can be appreciated. The out-of-plane Raman mode $\mathrm{A}_{1 \mathrm{~g}}$ and the in-plane $\mathrm{E}_{\mathrm{g}}$ one are sketched. The gray arrows represent the relative movement of the chalcogen atoms while the zirconium one remains at rest.

\section{Materials and Methods}

Large single crystals of $\mathrm{ZrS}_{2}$ and $\mathrm{ZrSe}_{2}$ were grown by chemical vapor transport (CVT) and characterized by powder X-ray diffraction and energy-dispersive X-ray spectroscopy (see Appendix A for further information). 
Thin layers of $\mathrm{ZrX}_{2}$ were obtained by mechanical exfoliation and deposited over a silicon substrate with $285 \mathrm{~nm}$ of thermally grown $\mathrm{SiO}_{2}$ (NOVA Electronic Materials LLC, Flower Mound, TX, USA). Exfoliation process was performed using an adhesive plastic film of $80 \mu \mathrm{m}$ thick from Ultron Systems (Ultron Systems, Inc., Moorpark, CA, USA). A plastic film piece was used to peel a freshly cleaved bulk $\mathrm{ZrX}_{2}$ crystal and the peeling process was repeated to obtain thinner flakes. Flakes were then deposited over a $\mathrm{Si} / \mathrm{SiO}_{2}$ substrate (root mean squared surface roughness $\approx 0.171 \mathrm{~nm}$ ) by attaching the adhesive piece over the surface and applying a gentle pressure. Before flake deposition, substrates were cleaned by sonication in a $\mathrm{H}_{2} \mathrm{O}: \mathrm{NH}_{4} \mathrm{OH}: \mathrm{H}_{2} \mathrm{O}_{2}$ (2:1:1) solution and rinsed in water. Finally, the adhesive piece was slowly removed from the sample and thin nanosheets were found and inspected over the substrate by optical microscopy, atomic force microscopy (AFM), and Raman spectroscopy. Exfoliation and measurements were performed in ambient conditions, while samples were kept under a vacuum in the meantime.

Optical images were obtained with a NIKON Eclipse LV-100 Optical microscope and AFM images were performed with a Nanoscope IVa Multimode Scanning Probe Microscope (Bruker, Karlsruhe, Germany) in tapping mode.

Raman spectra were acquired with a micro-Raman (model XploRA ONE from Horiba, Kyoto, Japan) with a grating of $2400 \mathrm{gr} / \mathrm{mm}$, slit of $50 \mu \mathrm{m}$, and hole of $500 \mu \mathrm{m}$. The employed wavelengths were $532 \mathrm{~nm}, 638 \mathrm{~nm}$, and $785 \mathrm{~nm}$. The power density of the laser used for spectra measured at $532 \mathrm{~nm}$ was $5.25 \mathrm{~mW} / \mu \mathrm{m}^{2}$ (bulk crystals) and $170 \mu \mathrm{W} / \mu \mathrm{m}^{2}$ (thin-layers), for spectra measured at $638 \mathrm{~nm}$ it was $7.58 \mathrm{~mW} / \mu \mathrm{m}^{2}$ (bulk crystals) and $410 \mu \mathrm{W} / \mu \mathrm{m}^{2}$ (thin-layers), and for those spectra measured at $785 \mathrm{~nm}$ it was $7.2 \mathrm{~mW} / \mu \mathrm{m}^{2}$ (bulk crystals).

\section{Results}

Bulk crystals of $\mathrm{ZrX}_{2}$ grown by CVT (see Appendix A) were mechanically exfoliated to obtain thin layers. Flakes with thicknesses ranging from hundreds to one nanometer were identified by optical contrast and AFM. Examples of thin layers can be seen in Figure 2 and Appendix B.

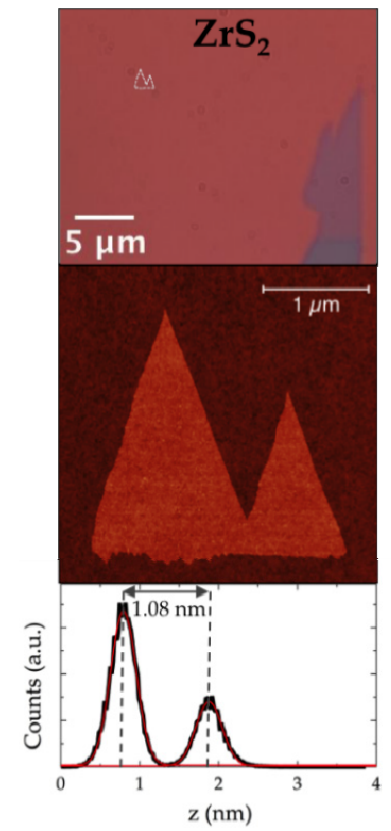

(a)

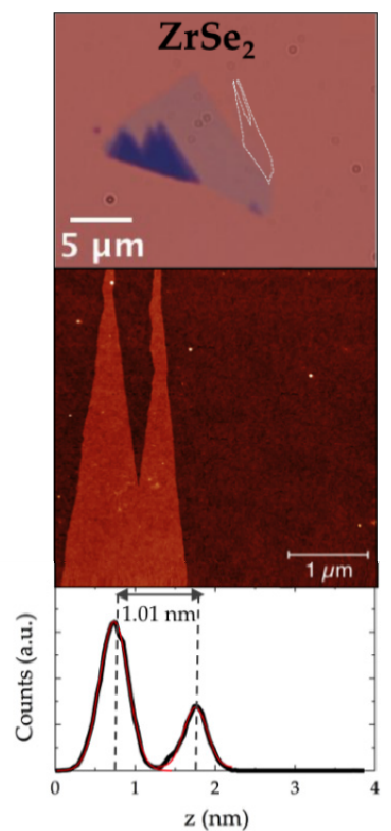

(b)

Figure 2. Optical image (top panel), atomic force microscopy measurement (middle panel) with the corresponding height histogram (bottom panel) for a monolayer of (a) $\mathrm{ZrS}_{2}$ and (b) $\mathrm{ZrSe}_{2}$. For clarity, the contour of the flake has been marked with a white line in the optical image. 
The obtained flakes were also characterized by Raman spectroscopy. In Figures 3 and 4 we report Raman spectra of $\mathrm{ZrS}_{2}$ and $\mathrm{ZrSe}_{2}$, respectively, for different thicknesses, while a broader spectral window is shown in Figures C1 and C4 (Appendix C). Note that the estimated number of layers may vary by \pm 1 layer due to an approximate estimation of the dead layer, as further discussed in Appendix B. Due to the overlap between the silicon peak and the $\mathrm{A}_{1 \mathrm{~g}}$ peak of $\mathrm{ZrS}_{2}$, in Figure $3 \mathrm{~b}$ we also report the Raman spectra of $\mathrm{ZrS}_{2}$ flakes deposited on a silicon substrate covered with $\mathrm{Ta}(3 \mathrm{~nm}) / \mathrm{Au}$ $(30 \mathrm{~nm})$. This coating masks the Si peak and allows a clearer view of the Raman mode for thin layers.

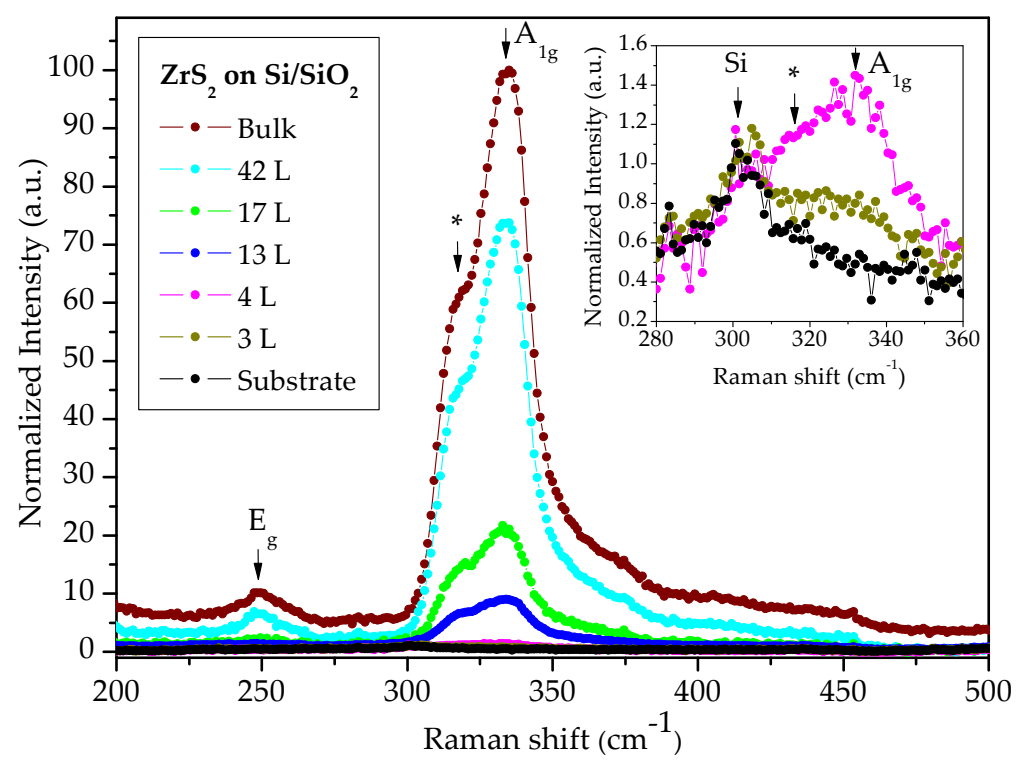

(a)

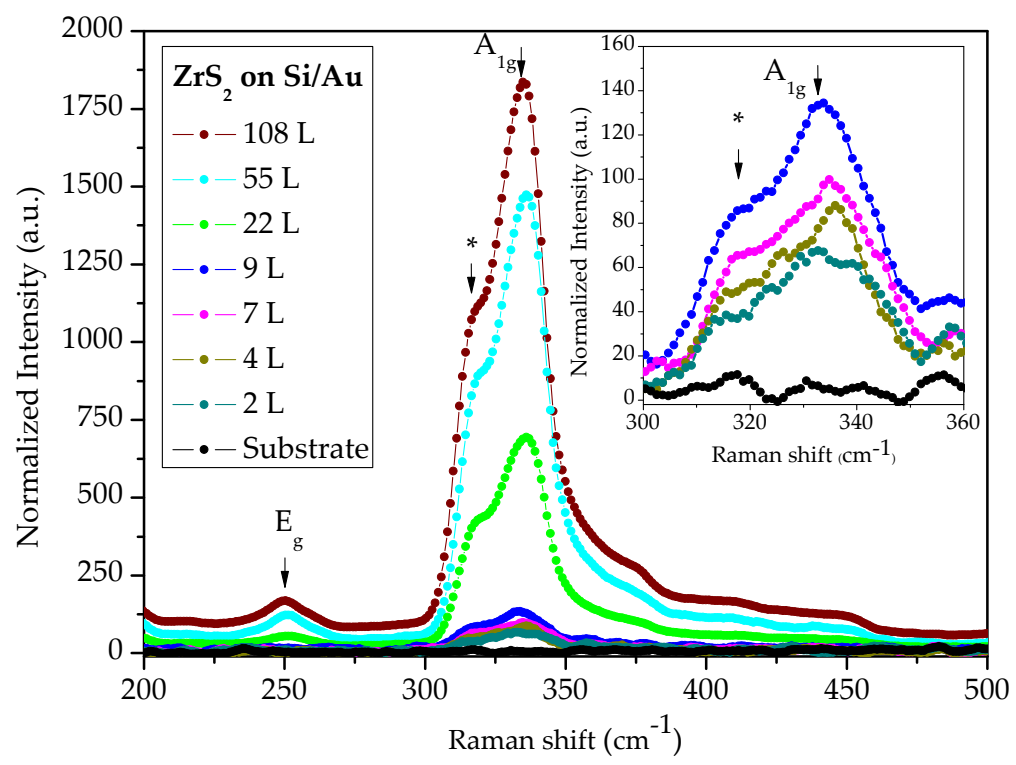

(b)

Figure 3. Thickness dependence of the Raman spectra for $\mathrm{ZrS}_{2}(\lambda=532 \mathrm{~nm})(\mathbf{a})$ on a silicon substrate with $285 \mathrm{~nm}$ of $\mathrm{SiO}_{2}$ and (b) on a silicon substrate covered with $\mathrm{Ta}(3 \mathrm{~nm}) / \mathrm{Au}(30 \mathrm{~nm})$. Inset: zoom of Raman spectra in the characteristic peak for thin layers. The intensity has been normalized to the height of the silicon phonon peak. The Raman modes $\mathrm{A}_{1 \mathrm{~g}}$ and $\mathrm{E}_{\mathrm{g}}$ are labeled. The shoulder marked with "*" is attributed to a broadening of the $A_{1 g}$ peak due to non-harmonic effects. 


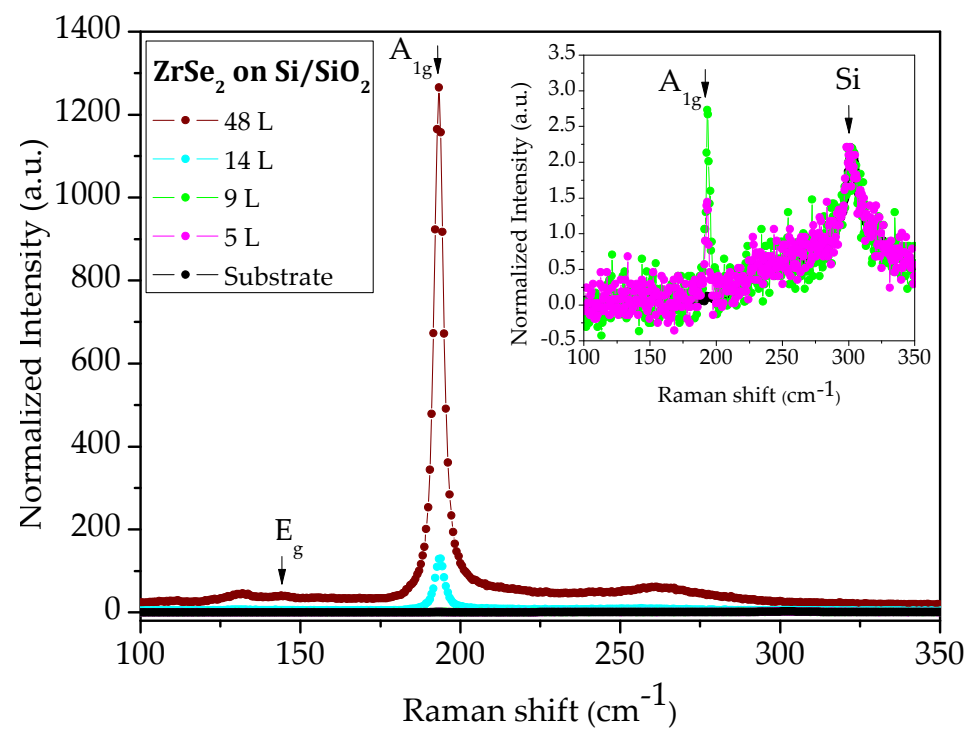

Figure 4. Thickness dependence of the Raman spectra for $\mathrm{ZrSe}_{2}(\lambda=638 \mathrm{~nm})$ on a silicon substrate with $285 \mathrm{~nm}$ of $\mathrm{SiO}_{2}$. Inset: zoom of Raman spectra in the $\mathrm{A}_{1 \mathrm{~g}}$ characteristic peak for the thinnest layers. The intensity has been normalized to the height of the silicon phonon peak.

In order to better show the Raman peaks of the thin layers, all the spectra have been normalized to the height of the silicon phonon peak (which is inversely proportional to the flake thickness), except for the spectrum of bulk crystal, which has been normalized to the $A_{1 g}$ peak. Bare spectra (counts/s) of Figures 3 and 4 are also shown in Figures C2, C3, and C5, and a detailed analysis of the fitted Raman peaks is presented in Tables C1-C3. Finally, a comparison between the Raman signal measured at different wavelengths $(532 \mathrm{~nm}, 638 \mathrm{~nm}$, and $785 \mathrm{~nm}$ ) is also provided in Appendix C (Figure C6), as well as the spectra obtained from the surface of non-cleaved and cleaved bulk crystals (Figure C7).

\section{Discussion}

Thin layers of $\mathrm{ZrX}_{2}$ have been obtained by mechanical exfoliation and inspected by optical and atomic force microscopy, as can be seen in Figure 2 and Appendix B. The estimation of the number of layers was calculated by dividing the AFM experimental height by the $c$ parameter of the unit cell (5.827 $\AA$ for $\mathrm{ZrS}_{2}$ and $6.1282 \AA$ for $\mathrm{ZrSe}_{2}$; see Appendix A). Nevertheless, as already observed in graphene, the experimental height of a monolayer is usually overestimated compared with the expected crystallographic one due to the presence of adsorbates, as water molecules, between the substrate and the thin layer [32]. As further discussed in Appendix B, this phenomenon could introduce an error of \pm 1 layer in the estimation of the number of layers, especially for thick flakes.

For Raman spectra, the in-plane mode $\left(\mathrm{E}_{\mathrm{g}}\right)$ and the out-of-plane mode $\left(\mathrm{A}_{1 \mathrm{~g}}\right)$ can be observed in the bulk and the thicker samples inspected (see Figures 3 and 4 and Appendix $\mathrm{C}$ ). For $\mathrm{ZrS}_{2}$, the obtained values are $249.7 \pm 0.8 \mathrm{~cm}^{-1}$ for the $\mathrm{E}_{\mathrm{g}}$ peak and $334.0 \pm 1.4 \mathrm{~cm}^{-1}$ for the $\mathrm{A}_{1 \mathrm{~g}}$ peak. The broadening of the $\mathrm{A}_{1 \mathrm{~g}}$ peak at $319.9 \pm 0.6 \mathrm{~cm}^{-1}$ (denoted with "** in Figure 3) is attributed to non-harmonic effects (i.e., the phonon can emit acoustic phonons, with practically no energy, that give rise to that huge broadening) while some authors ascribed it to the infrared mode $\mathrm{A}_{2 \mathrm{u}}$ that would be coupled to the Raman spectra thanks to the long-range Coulomb forces due to the charges on atoms [33]. However, as recently reported, the IR mode must be at a higher frequency (it has been observed to be around $500 \mathrm{~cm}^{-1}$ [34]) since the zirconium atom vibrates against the sulfur atom and the reduced mass is much higher. Further discussion can be found in Appendix D. Regarding $\mathrm{ZrSe}_{2}$, a small peak appears at $145.80 \pm 0.19 \mathrm{~cm}^{-1}$ for the $\mathrm{E}_{\mathrm{g}}$ peak and a clear one at $195.5 \pm 0.2 \mathrm{~cm}^{-1}$ for the $\mathrm{A}_{1 \mathrm{~g}}$ one. These values are in good accordance with the ones previously reported in the literature [31]. Moreover, in the wider spectra shown in Figure C1 (see Appendix C), a broad band at $682.8 \pm 0.5 \mathrm{~cm}^{-1}$ and three 
peaks at $109 \pm 1 \mathrm{~cm}^{-1}, 140.0 \pm 0.3 \mathrm{~cm}^{-1}$, and $193.2 \pm 0.3 \mathrm{~cm}^{-1}$ can be observed for $\mathrm{ZrS}_{2}$, while for $\mathrm{ZrSe}_{2}$ (Figure C4) there are four peaks at $107.4 \pm 0.3 \mathrm{~cm}^{-1}, 133.61 \pm 0.09 \mathrm{~cm}^{-1}, 243.09 \pm 0.17 \mathrm{~cm}^{-1}$, and $267.61 \pm 0.10 \mathrm{~cm}^{-1}$. All these peaks can be attributed to the density of two phonon states of $\mathrm{ZrX}_{2}$ [35]. For thin layers, the Raman peaks coming from the silicon substrate are detected as well. In particular, we observed the silicon phonon peak at $520.71 \pm 0.03 \mathrm{~cm}^{-1}$ and second-order Raman peaks as the broad peak centered at $301 \pm 1 \mathrm{~cm}^{-1}$ and the Raman band at $950 \mathrm{~cm}^{-1}$, in accordance with the reported ones in the literature [36].

As qualitatively shown in Figures 3 and 4 and quantitatively analyzed in Tables C1-C3, we find that when reducing the thickness the intensity of the Raman peaks decreases; in strict contrast with what is observed in group VI TMDCs as $\mathrm{MoS}_{2}$ [26], no significant shift is found in their position. Moreover, the relative intensity between the $\mathrm{E}_{\mathrm{g}}$ peak and the $\mathrm{A}_{1 \mathrm{~g}}$ one is reduced in a non-monotonic way and, for the thinner layers, only the out-of-plane mode can be resolved. Raman signal has been detected from bulk down to three layers for $\mathrm{ZrS}_{2}$ and five layers for $\mathrm{ZrSe} \mathrm{S}_{2}$ on a Si/SiO $\mathrm{Sibstrate}_{2}$ and down to two layers for $\mathrm{ZrS}_{2}$ on a silicon substrate covered with $\mathrm{Ta}(3 \mathrm{~nm})$ and $\mathrm{Au}(30 \mathrm{~nm})$. Indeed, the Au substrate coating masks the Si peak that appears at $300 \mathrm{~cm}^{-1}$ and that overlaps with $A_{1 \mathrm{~g}}$ peak of $\mathrm{ZrS}_{2}$, thus allowing a clearer detection of the $\mathrm{ZrS}_{2}$ mode.

In order to optimize the observed Raman signal for each material, Raman spectra were measured at three different wavelengths $(532 \mathrm{~nm}, 638 \mathrm{~nm}$, and $785 \mathrm{~nm})$ on a thick flake and shown in Figure C6. From the three wavelengths inspected, the optimum ones are found to be $532 \mathrm{~nm}$ for $\mathrm{ZrS}_{2}$ and $638 \mathrm{~nm}$ for $\mathrm{ZrSe}_{2}$. Both materials have an indirect band gap. In the case of $\mathrm{ZrS}_{2}$, the direct band gap is around $2 \mathrm{eV}(620 \mathrm{~nm})$, while the indirect one is at $1.4 \mathrm{eV}(885 \mathrm{~nm})$. On the other hand, $\mathrm{ZrSe}_{2}$ has a direct gap around $1.2 \mathrm{eV}(1030 \mathrm{~nm})$ and an indirect gap of $0.7 \mathrm{eV}(1770 \mathrm{~nm})$ [35]. Thus, we can ascribe the signal enhancement at these wavelengths to two factors: a resonance effect and an increase of the absorption (more volume contributing to the scattering). However, the thickness of the $\mathrm{SiO}_{2}$ layer may also play a role, as observed in the Interference Enhanced Raman Scattering (IERS) [24].

In addition, no major changes are observed in the Raman spectra of freshly cleaved and uncleaved bulk samples (Figure C7). However, partial oxidation of the surface cannot be neglected since it is already stated that, with time, bulk materials are subjected to a surface oxidation at room temperature and in ambient conditions [37]. The amount of relative surface oxidation as well as the influence of the substrate is expected to be larger in thin layers than in bulk samples since the ratio between the surface and the volume is higher. Moreover, it should be noted that, especially for thin flakes, special care had to be taken regarding the power density of the laser used during measurements and the acquisition time. Indeed, even using a low laser power density $\left(170 \mu \mathrm{W} / \mu \mathrm{m}^{2}\right)$, flakes were revealed to be easily degraded during the measurement if the exposition time was not sufficiently short. This effect was observed to be more dramatic for $\mathrm{ZrSe}_{2}$ (on the order of seconds) than $\mathrm{ZrS}_{2}$ (on the order of minutes). This tendency is also reported and coincides with the one observed in bulk crystals of $\mathrm{ZrX}_{2}$ [38]. A more extended discussion on flakes degradation and oxidation is reported in Appendix E.

Finally, we also found that no Raman signal could be obtained at all from non-freshly exfoliated $\mathrm{ZrSe}_{2}$ thin layers. This could be attributed to the possible oxidation or degradation of the flakes in air, as it has been observed in $\mathrm{HfS}_{2}$ [39] or $\mathrm{NbSe}_{2}$ [40]. Despite the fact that $\mathrm{ZrSe}_{2}$ appeared to be more sensitive to ambient conditions than $\mathrm{ZrS}_{2}$, we cannot exclude the possibility that monolayers and thin layers of both materials may be unstable in air. In order to avoid this phenomenon, further research should be performed in encapsulated samples or under inert gas conditions [40].

\section{Conclusions}

In conclusion, mechanical exfoliation of $\mathrm{ZrX}_{2}(X=S$, Se) from bulk to the monolayer was reported for the first time and we studied the dimensionality dependence of the Raman spectra in ambient conditions. Raman spectra were observed down to two layers for $\mathrm{ZrS}_{2}$ and to five layers for $\mathrm{ZrSe}_{2}$. In contrast to other TMDCs, such as $2 \mathrm{H}-\mathrm{MoS}_{2}$, no shift was found in the Raman peaks as a function of the number of layers. In addition, the absence of photoluminescence in the range of thicknesses studied 
in this work is in accordance with the nonexistence of an indirect-to-direct band-gap transition with the dimensionality, thus confirming the theoretical predictions in these materials [14,16]. These results represent one of the first steps towards the investigation of $\mathrm{ZrX} \mathrm{X}_{2}$ properties in the two-dimensional limit that, until now, remained mostly unexplored.

Acknowledgments: We acknowledge the financial support from the Spanish MINECO (MAT2014-56143-R co-financed by FEDER, Excellence Unit “María de Maeztu” MDM- 2015-0538), and the Generalitat Valenciana (Programs Prometeo and ISIC- NANO). Samuel Mañas-Valero thanks the Spanish MECD for a F.P.U. (Formación de Profesorado Universitario fellowship FPU014/04407). Marta Galbiati acknowledges the European Union Horizon 2020 Marie Curie Actions under the project SPIN2D (H2020/2014-659378). The authors are grateful to the Atomic Spectroscopy, Glass-Blowing, and Microscopy sections at Central Support Service in the Experimental Research SCSIE of the University of Valencia for their constant and kind support. We thank Efrén Navarro-Moratalla, Alicia Forment-Aliaga, Sergio Tatay and Eugenio Coronado for helpful discussions and Ángel López-Muñoz, José María Martínez-Agudo, Alejandra Soriano-Portillo, José Vicente Usagre-Fernández and Eva Tormos-Feliu for their technical support.

Author Contributions: Samuel Mañas-Valero and Marta Galbiati conceived and designed the experiments; Samuel Mañas-Valero performed the crystal growth and bulk characterization; Samuel Mañas-Valero, Víctor García-López, and Marta Galbiati exfoliated and characterized the obtained thin-layers; Samuel Mañas-Valero, Marta Galbiati, and Andrés Cantarero interpreted the Raman data; Samuel Mañas-Valero and Marta Galbiati wrote the paper. All authors discussed the results and contributed to the final version of the manuscript.

Conflicts of Interest: The authors declare no conflict of interest.

\section{Appendix A. Crystal Growth of $\mathrm{ZrX}_{2}$}

The synthesis of $\mathrm{ZrX} \mathrm{X}_{2}$ was performed following a typical solid state reaction. Powders of $99.5 \%$ $\mathrm{Zr}$ from abcr GmbH (Karlsruhe, Germany), 99.98\% S from Sigma-Aldrich (Saint Louis, MO, USA), and $99.999 \%$ Se from Alfa-Aesar (Lancashire, UK) were mixed in a stoichiometric ratio, sealed in an evacuated quartz ampoule $\left(\mathrm{P} \sim 5 \times 10^{-5} \mathrm{mbar}\right.$, length $=25 \mathrm{~cm}$, internal diameter $\left.=1.5 \mathrm{~cm}\right)$ and heated from room temperature to $900{ }^{\circ} \mathrm{C}$ at $1.5^{\circ} \mathrm{C} / \mathrm{min}$. Then, the temperature was kept constant for eight days and slowly cooled down $\left(0.07^{\circ} \mathrm{C} / \mathrm{min}\right)$.

For obtaining large crystals, $4 \mathrm{mmol}$ of the previous material was mixed with $\mathrm{I}_{2}$ as a transport agent $\left(\left[\mathrm{I}_{2}\right] \sim 5 \mathrm{mg} / \mathrm{cm}^{3}\right)$ in an evacuated quartz ampoule $\left(\mathrm{P} \sim 5 \times 10^{-5}\right.$ mbar, length $=50 \mathrm{~cm}$, internal diameter $=1.5 \mathrm{~cm}$ ). The quartz tube was placed inside a three-zone furnace with the material in the leftmost zone. The other two zones were heated up in $3 \mathrm{~h}$ from room temperature to $700{ }^{\circ} \mathrm{C}$ and kept for two days. After this, the leftmost side was heated up to $750{ }^{\circ} \mathrm{C}$ in $3 \mathrm{~h}$ and it was established in the three-zone furnace a gradient of $750{ }^{\circ} \mathrm{C} / 700{ }^{\circ} \mathrm{C} / 725^{\circ} \mathrm{C}$. Then the temperature was kept constant for 20 days and cooled down naturally. As shown in the insets of Figure A1, with this process we could obtain crystals with a length up to some centimeters.

The obtained crystals were analyzed by EDX and powder X-ray diffraction. The amount of elements obtained in weight was $\mathrm{Zr}: 57.7 \% \pm 1.4 \%$ and $\mathrm{S}: 42.4 \% \pm 1.0 \%$ for $\mathrm{ZrS}_{2}$ and $\mathrm{Zr}: 35.7 \% \pm 1.2 \%$ and Se: $64.3 \% \pm 1.7 \%$ for $\mathrm{ZrSe}_{2}$. These values are in good agreement with the expected ones (for $\mathrm{ZrS}_{2}$, $\mathrm{Zr}: 58.4 \%$ and S: $41.6 \%$; for $\mathrm{ZrSe} 2, \mathrm{Zr}$ : $36 \%$ and Se: $64 \%$ ). The refinement of the $\mathrm{X}$-ray pattern revealed a trigonal crystal system with a P-3m1 space group and a unit cell determined by $\alpha=\beta=90^{\circ}$ and $\gamma=120^{\circ}$ and $\mathrm{a}=\mathrm{b}=3.6628(5) \AA, \mathrm{c}=5.8270(10) \AA$ for $\mathrm{ZrS}_{2}$ and $\mathrm{a}=\mathrm{b}=3.7711(4) \AA, \mathrm{c}=6.1282(9) \AA$ for $\mathrm{ZrSe}_{2}$. The obtained results are in accordance with the ones reported in the literature [30,41]. 


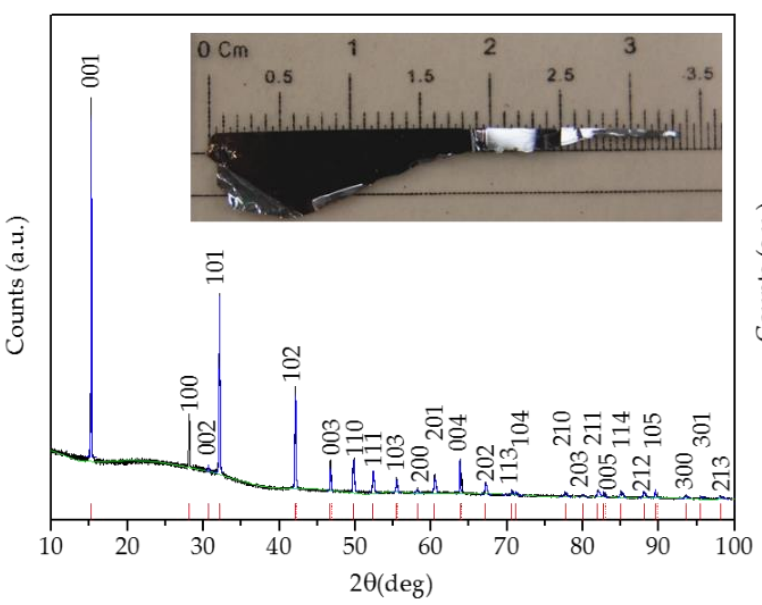

(a)

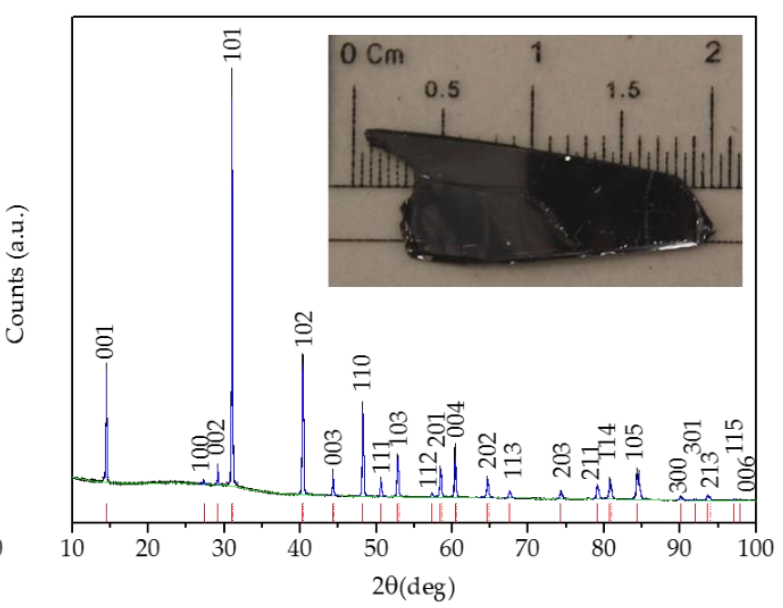

(b)

Figure A1. XRPD experimental pattern (black) and corresponding fit (peaks in blue and background in green) for $\mathrm{ZrX}_{2}$ crystals. For simplicity, the fit has been marked with red lines. (a) Pattern of $\mathrm{ZrS}_{2}$. Inset: Photography of a $\mathrm{ZrS}_{2}$ crystal. The fit gives as a result: $\mathrm{a}=\mathrm{b}=3.6628(5) \AA$ and $\mathrm{c}=5.8270(10) \AA$, trigonal crystal system with $\mathrm{P}-3 \mathrm{~m} 1$ space group, $\chi^{2}=3.8 \cdot 10^{-6}$, and a Snyder's figure of merit of 41.64 . (b) Pattern of $\mathrm{ZrSe}_{2}$. Inset: Photography of $\mathrm{ZrSe}_{2}$ crystal. The fit gives as a result: $\mathrm{a}=\mathrm{b}=3.7722(4) \AA$ and $\mathrm{c}=6.1310(9) \AA$, trigonal crystal system with $\mathrm{P}-3 \mathrm{~m} 1$ space group, $\chi^{2}=2.4 \times 10^{-6}$, and a Snyder's figure of merit of 50.16 .

\section{Appendix B. Thin Layers of $\mathrm{ZrX}_{2}$ Obtained by Mechanical Exfoliation}

Optical images and AFM measurements in layers with different thicknesses of mechanically exfoliated $\mathrm{ZrX}_{2}$ are shown in Figure B1 for $\mathrm{ZrS}_{2}$ and in Figure B2 for $\mathrm{ZrSe}_{2}$.

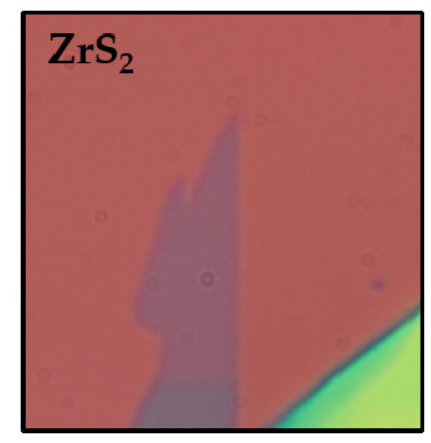

(a)

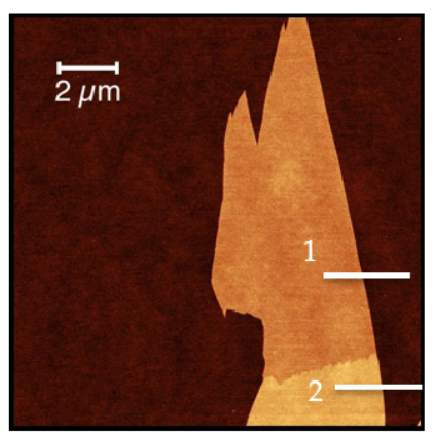

(b)

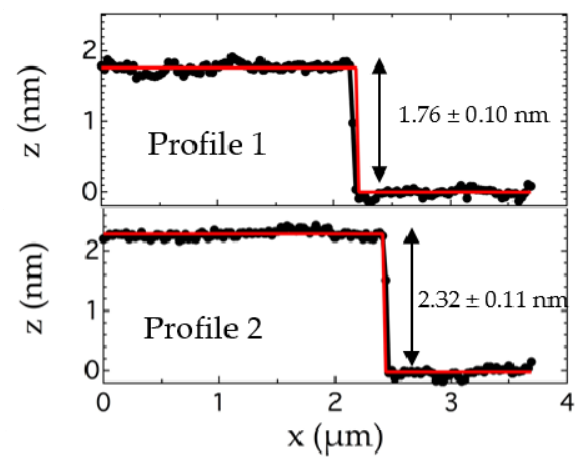

(c)

Figure B1. (a) Optical microscope and (b) AFM measurement with (c) the corresponding thickness profile for $\mathrm{ZrS}_{2}$ flakes.

Figure B1 reports the optical image and AFM measurement of a thin flake of $\mathrm{ZrS}_{2}$. From the AFM profile it is possible to estimate the thickness of the thinner part of the flake to be $1.76 \pm 0.10 \mathrm{~nm}$ (profile 1) and the thickness of the thicker part to be $2.32 \pm 0.11 \mathrm{~nm}$ (profile 2). One has to note that thickness estimation has been done on the fitting of the average of five different contiguous profiles. As already reported in the literature, a "dead layer" is often observed in mechanically exfoliated flakes due to the ever-present layer of absorbed water, which remains captured between the flake and the substrate [31]. From Figure 2a we found the "dead layer" to be about $5 \AA$ and from Figure B1 we find a similar value (about $5.9 \AA$ ), thus allowing us to estimate the previous flakes to be two and three layers thick, respectively. However, it must be noted that, due to the difficulty in the estimation of the "dead 
layer" and its value comparable to the thickness of one layer of the material, an error of \pm 1 layer could be found in the layers estimation. While the thickness of the first layer is always critical due to the adsorbates presence, the step between the two layers $(\approx 0.56 \mathrm{~nm} \pm 0.15 \mathrm{~nm})$ is found to be well in agreement with the $c$ parameter of the unit cell expected for this material $(5.827 \AA$ ).

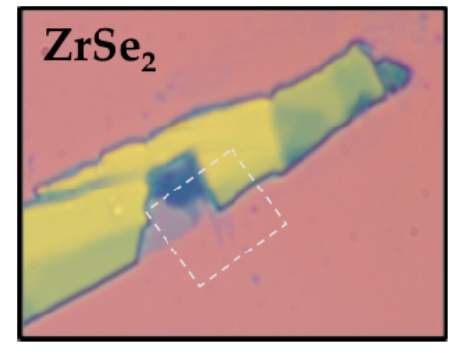

(a)

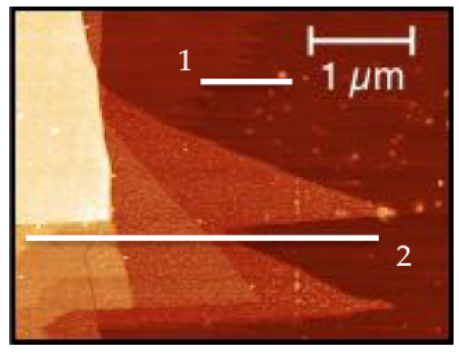

(b)

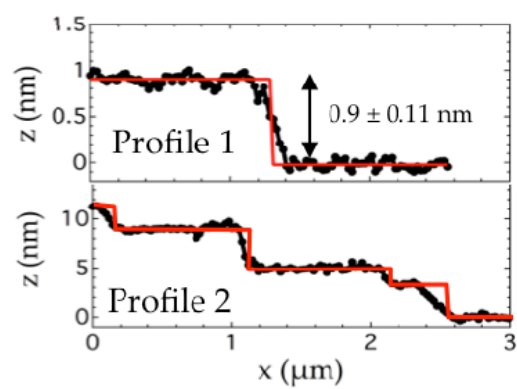

(c)

Figure B2. (a) Optical microscope and (b) AFM measurement of the dotted box in (a) with (c) the corresponding thickness profile for $\mathrm{ZrSe}_{2}$ flakes.

Figure B2 reports the optical image and AFM measurement of thin flakes of $\mathrm{ZrSe}_{2}$. From the first AFM profile we can estimate the thickness of the thin layer to be $0.90 \pm 0.11 \mathrm{~nm}$. This is compatible with a monolayer and a "dead layer" of about $3 \AA$ A. Flakes measured in profile 2 are thicker and they measure, from right to left: $3.5 \pm 0.2 \mathrm{~nm}, 4.8 \pm 0.3 \mathrm{~nm}, 9.1 \pm 0.3 \mathrm{~nm}$ and $12.0 \pm 0.2 \mathrm{~nm}$. Considering the "dead layer" of $3 \AA$ and the $c$ parameter of the unit cell of $6.1310 \AA$, they would correspond to five, seven, 14, and $19 \mathrm{ZrSe}_{2}$ layers, respectively. Again, in the estimation of the number of layers of these thicker flakes an error of \pm 1 layers could occur. Nevertheless, the small value of the "dead layer" found in this case should limit this eventuality.

\section{Appendix C. Raman Spectra}

Raman spectra with a broader spectral window for $\mathrm{ZrS}_{2}$ are presented in Figure C1. All spectra for thin layers have been normalized to the silicon phonon peak, which appears at $520.71 \pm 0.03 \mathrm{~cm}^{-1}$, except for the spectrum of bulk crystal, which has been normalized to the $A_{1 g}$ peak.

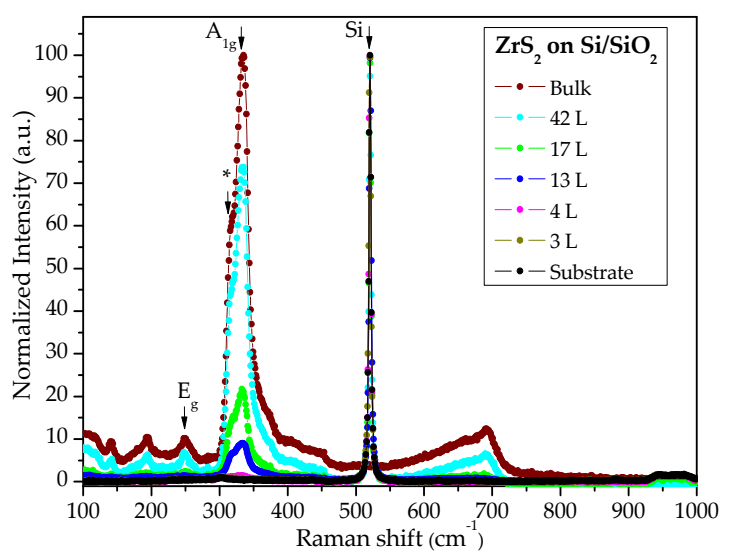

(a)

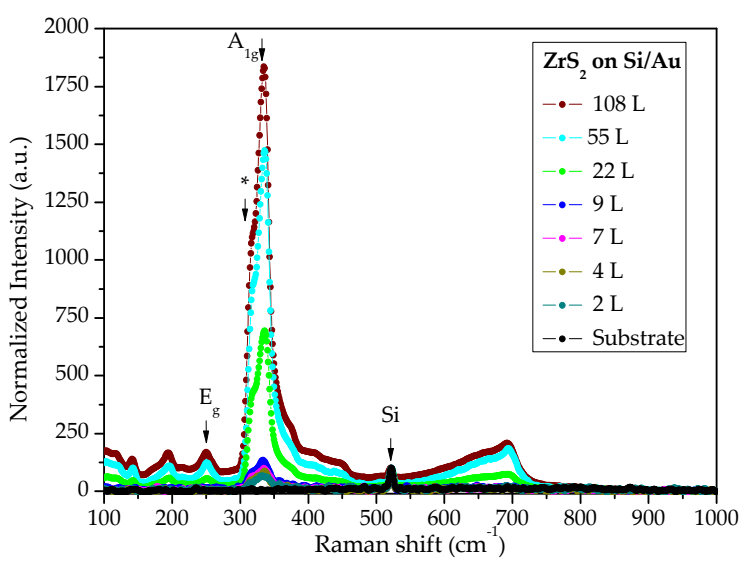

(b)

Figure C1. Thickness dependence of the Raman spectra for $\mathrm{ZrS}_{2}(\lambda=532 \mathrm{~nm})(\mathbf{a})$ on a silicon substrate with $285 \mathrm{~nm}$ of $\mathrm{SiO}_{2}$ and (b) on a silicon substrate covered with $\mathrm{Ta}(3 \mathrm{~nm}) / \mathrm{Au}(30 \mathrm{~nm})$. The Raman modes $\mathrm{A}_{1 \mathrm{~g}}$ and $\mathrm{E}_{\mathrm{g}}$ are labeled. The shoulder marked with "*" is attributed to a broadening of the $\mathrm{A}_{1 \mathrm{~g}}$ peak due to non-harmonic effects. 
Figure $\mathrm{C} 2$ corresponds to the bare spectra (in counts/s) for $\mathrm{ZrS}_{2}$ on a $\mathrm{Si} / \mathrm{SiO}_{2}$ substrate without the normalization to the Si phonon peak, in contrast to the spectra shown in Figure 3 and Figure C1a. The corresponding values for the fitting of the $\mathrm{E}_{\mathrm{g}}$ and $\mathrm{A}_{1 \mathrm{~g}}$ are summarized in Table $\mathrm{C} 1$.

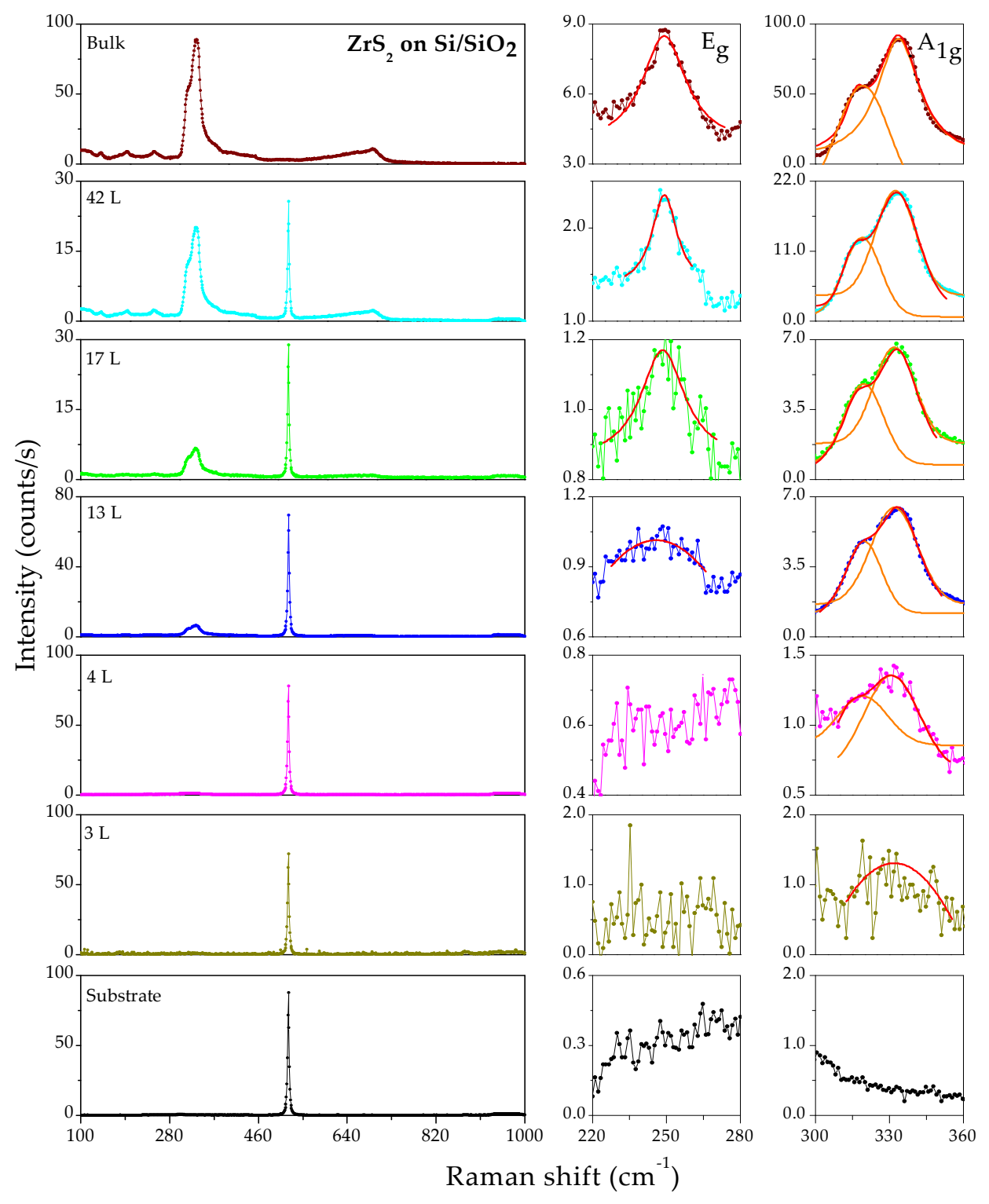

Figure C2. Thickness dependence of the Raman spectra for $\mathrm{ZrS}_{2}$ on a $\mathrm{Si} / \mathrm{SiO}_{2}$ substrate $(\lambda=532 \mathrm{~nm})$. Broad range spectra as well as zooms in the region of the $\mathrm{A}_{1 \mathrm{~g}}$ and $\mathrm{E}_{\mathrm{g}}$ modes with their corresponding fittings are presented. Fitting results are given in Table C1. 
Table C1. Thickness dependence of the fitted parameters (position, intensity, and FWHM) of the $\mathrm{E}_{\mathrm{g}}$ and $\mathrm{A}_{1 \mathrm{~g}}$ modes obtained from the Raman spectra for $\mathrm{ZrS}{ }_{2}$ on a $\mathrm{Si} / \mathrm{SiO}_{2}$ substrate $(\lambda=532 \mathrm{~nm})$ presented in Figure $\mathrm{C} 2$.

\begin{tabular}{|c|c|c|c|c|c|c|c|c|c|}
\hline \multirow{2}{*}{$\begin{array}{l}\text { Thickness } \\
\text { ( } \pm 1 \text { Layer) }\end{array}$} & \multicolumn{3}{|c|}{$E_{g}$} & \multicolumn{3}{|c|}{ * } & \multicolumn{3}{|c|}{$A_{1 g}$} \\
\hline & $\begin{array}{l}\text { Position } \\
\left(\mathrm{cm}^{-1}\right)\end{array}$ & $\begin{array}{l}\text { Intensity } \\
\text { (Counts/s) }\end{array}$ & $\begin{array}{c}\text { FWHM } \\
\left(\mathrm{cm}^{-1}\right)\end{array}$ & $\begin{array}{l}\text { Position } \\
\left(\mathrm{cm}^{-1}\right)\end{array}$ & $\begin{array}{l}\text { Intensity } \\
\text { (Counts/s) }\end{array}$ & $\begin{array}{c}\text { FWHM } \\
\left(\mathrm{cm}^{-1}\right)\end{array}$ & $\begin{array}{c}\text { Position } \\
\left(\mathrm{cm}^{-1}\right)\end{array}$ & $\begin{array}{l}\text { Intensity } \\
\text { (Counts/s) }\end{array}$ & $\begin{array}{l}\text { FWHM } \\
\left(\mathrm{cm}^{-1}\right)\end{array}$ \\
\hline Bulk & $249.1 \pm 0.3$ & 8.5 & $22 \pm 2$ & $319.4 \pm 0.4$ & 55.9 & $7.6 \pm 0.4$ & $333.7 \pm 0.3$ & 89.5 & $20.8 \pm 1.0$ \\
\hline $42 \mathrm{~L}$ & $249.2 \pm 0.2$ & 2.4 & $12.5 \pm 0.6$ & $318.9 \pm 0.3$ & 13.1 & $7.6 \pm 0.4$ & $332.45 \pm 0.15$ & 20.5 & $23.7 \pm 0.8$ \\
\hline $17 \mathrm{~L}$ & $248.5 \pm 0.5$ & 1.2 & $22 \pm 6$ & $319.6 \pm 0.4$ & 4.8 & $7.9 \pm 0.4$ & $332.02 \pm 0.16$ & 6.6 & $23.5 \pm 0.8$ \\
\hline $13 \mathrm{~L}$ & $245.8 \pm 0.9$ & 1.0 & $200 \pm 30^{1}$ & $319.6 \pm 0.2$ & 4.7 & $7.0 \pm 0.1$ & $331.99 \pm 0.19$ & 6.4 & $24.3 \pm 0.8$ \\
\hline $4 \mathrm{~L}$ & - & - & - & $319 \pm 2$ & 1.2 & $10 \pm 20^{1}$ & $330.9 \pm 1.3$ & 1.4 & $22 \pm 4$ \\
\hline $3 \mathrm{~L}$ & - & - & - & - & - & - & $331.9 \pm 1.3$ & 1.3 & $140 \pm 180^{1}$ \\
\hline
\end{tabular}

${ }^{1}$ For the thinner layers, which present a poor signal-to-noise ratio, fitting leads to a broader peak (as can be seen in the FWHM), thus making an accurate estimation of the peak position more difficult. * denotes the left shoulder observed in the $\mathrm{A}_{1 \mathrm{~g}}$ peak.

Table C2. Thickness dependence of the fitted parameters (position, intensity, and FWHM) of the $\mathrm{E}_{\mathrm{g}}$ and $\mathrm{A}_{1 \mathrm{~g}}$ modes obtained from the Raman spectra for $\mathrm{ZrS} \mathrm{S}_{2}$ on a $\mathrm{Si} / \mathrm{Au}$ substrate $(\lambda=532 \mathrm{~nm})$ presented in Figure C3.

\begin{tabular}{|c|c|c|c|c|c|c|c|c|c|}
\hline \multirow{2}{*}{$\begin{array}{l}\text { Thickness } \\
\text { ( } \pm 1 \text { Layer) }\end{array}$} & \multicolumn{3}{|c|}{$E_{g}$} & \multicolumn{3}{|c|}{ * } & \multicolumn{3}{|c|}{$\mathbf{A}_{1 \mathrm{~g}}$} \\
\hline & $\begin{array}{l}\text { Position } \\
\left(\mathrm{cm}^{-1}\right)\end{array}$ & $\begin{array}{l}\text { Intensity } \\
\text { (Counts/s) }\end{array}$ & $\begin{array}{l}\text { FWHM } \\
\left(\mathrm{cm}^{-1}\right)\end{array}$ & $\begin{array}{l}\text { Position } \\
\left(\mathrm{cm}^{-1}\right)\end{array}$ & $\begin{array}{l}\text { Intensity } \\
\text { (Counts/s) }\end{array}$ & $\begin{array}{l}\text { FWHM } \\
\left(\mathrm{cm}^{-1}\right)\end{array}$ & $\begin{array}{c}\text { Position } \\
\left(\mathrm{cm}^{-1}\right)\end{array}$ & $\begin{array}{l}\text { Intensity } \\
\text { (counts/s) }\end{array}$ & $\begin{array}{l}\text { FWHM } \\
\left(\mathrm{cm}^{-1}\right)\end{array}$ \\
\hline $108 \mathrm{~L}$ & $249.84 \pm 0.17$ & 6.1 & $18.3 \pm 1.0$ & $320.5 \pm 0.5$ & 42.5 & $10.1 \pm 1.2$ & $334.5 \pm 0.2$ & 63.6 & $23.2 \pm 1.0$ \\
\hline $55 \mathrm{~L}$ & $250.8 \pm 0.2$ & 2.6 & $17.1 \pm 1.2$ & $320 \pm 2$ & 19.6 & $7.5 \pm 0.5$ & $334.8 \pm 0.2$ & 31.5 & $23.7 \pm 1.0$ \\
\hline $22 \mathrm{~L}$ & $250.5 \pm 0.3$ & 2.3 & $20.1 \pm 1.9$ & $320.5 \pm 0.3$ & 19.1 & $8.0 \pm 0.5$ & $335.5 \pm 0.2$ & 29.4 & $24.6 \pm 0.9$ \\
\hline $9 \mathrm{~L}$ & - & - & - & $321 \pm 2$ & 2.1 & $10 \pm 4$ & $333.9 \pm 0.5$ & 2.9 & $25 \pm 3$ \\
\hline $7 \mathrm{~L}$ & - & - & - & $319.9 \pm 0.9$ & 1.7 & $14 \pm 4$ & $335.3 \pm 0.8$ & 2.1 & $30 \pm 4$ \\
\hline $4 \mathrm{~L}$ & - & - & - & $320 \pm 3$ & 1.2 & $13 \pm 4$ & $336.1 \pm 1.4$ & 1.7 & $12 \pm 2$ \\
\hline $2 \mathrm{~L}$ & - & - & - & $319 \pm 5$ & 0.7 & $100 \pm 700^{1}$ & $334.5 \pm 1.6$ & 1.1 & $50 \pm 20^{1}$ \\
\hline
\end{tabular}

${ }^{1}$ For the thinner layers, which present a poor signal-to-noise ratio, fitting leads to a broader peak (as can be seen in the FWHM), thus making an accurate estimation of the peak position more difficult. * denotes the left shoulder observed in the $\mathrm{A}_{1 \mathrm{~g}}$ peak. 
In Figure C3, the Raman bare spectra (in counts/s) for flakes with different thicknesses of $\mathrm{ZrS}_{2}$ are shown. Due to the overlapping between the silicon peak and the $\mathrm{A}_{1 \mathrm{~g}}$ peak of $\mathrm{ZrS}_{2}$, Raman spectra of thin flakes of $\mathrm{ZrS}_{2}$ were studied on a silicon substrate covered with $\mathrm{Ta}(3 \mathrm{~nm}) / \mathrm{Au}(30 \mathrm{~nm})$. The corresponding values for the fitting of the $\mathrm{E}_{\mathrm{g}}$ and $\mathrm{A}_{1 \mathrm{~g}}$ are summarized in Table $\mathrm{C} 2$.
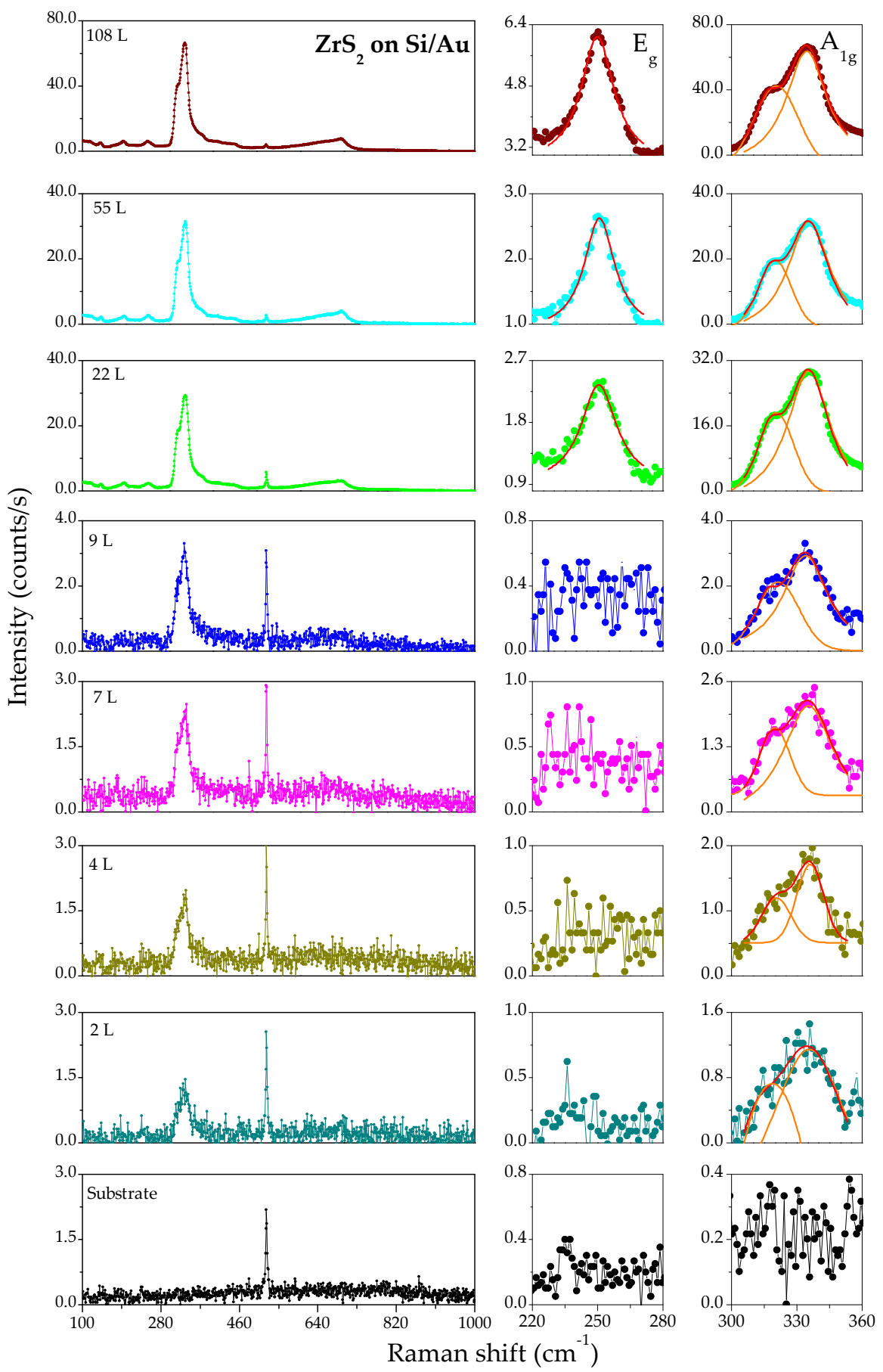

Figure C3. Thickness-dependence of the Raman spectra for $\mathrm{ZrS}_{2}$ on a Si / Au substrate $(\lambda=532 \mathrm{~nm})$. Broad range spectra as well as zooms in the region of the $\mathrm{A}_{1 \mathrm{~g}}$ and $\mathrm{E}_{\mathrm{g}}$ modes with their corresponding fitting are presented. Fitting results are given in Table $\mathrm{C} 2$.

Raman spectra with a broader spectral window for $\mathrm{ZrSe}_{2}$ are presented in Figure C4. All spectra have been normalized to the silicon phonon peak, which appears at $520.71 \pm 0.03 \mathrm{~cm}^{-1}$. 


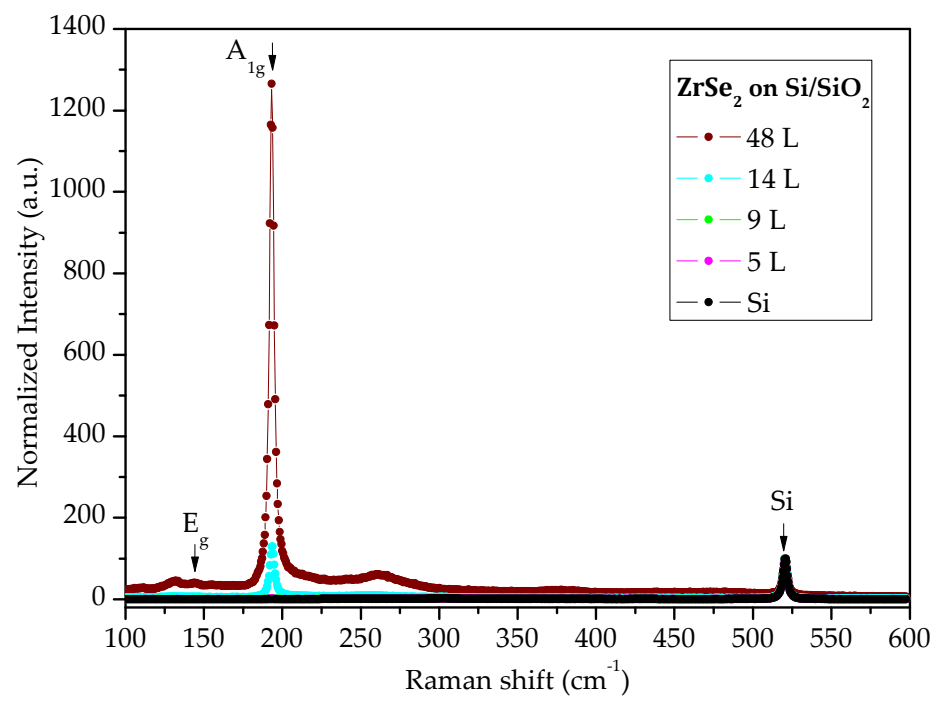

Figure C4. Thickness dependence of the Raman spectra for $\mathrm{ZrSe}_{2}(\lambda=638 \mathrm{~nm})$ on a silicon substrate with $285 \mathrm{~nm}$ of $\mathrm{SiO}_{2}$. The Raman modes $\mathrm{A}_{1 \mathrm{~g}}$ and $\mathrm{E}_{\mathrm{g}}$ are labeled.

Figure $\mathrm{C} 5$ corresponds to the bare spectra (in counts/s) for $\mathrm{ZrSe} 2$ on a $\mathrm{Si} / \mathrm{SiO}_{2}$ substrate without the normalization to the Si phonon peak, in contrast to the spectra shown in Figure 4 and Figure $C 4$. The corresponding values for the fitting of the $\mathrm{E}_{\mathrm{g}}$ and $\mathrm{A}_{1 \mathrm{~g}}$ are summarized in Table $\mathrm{C} 3$.

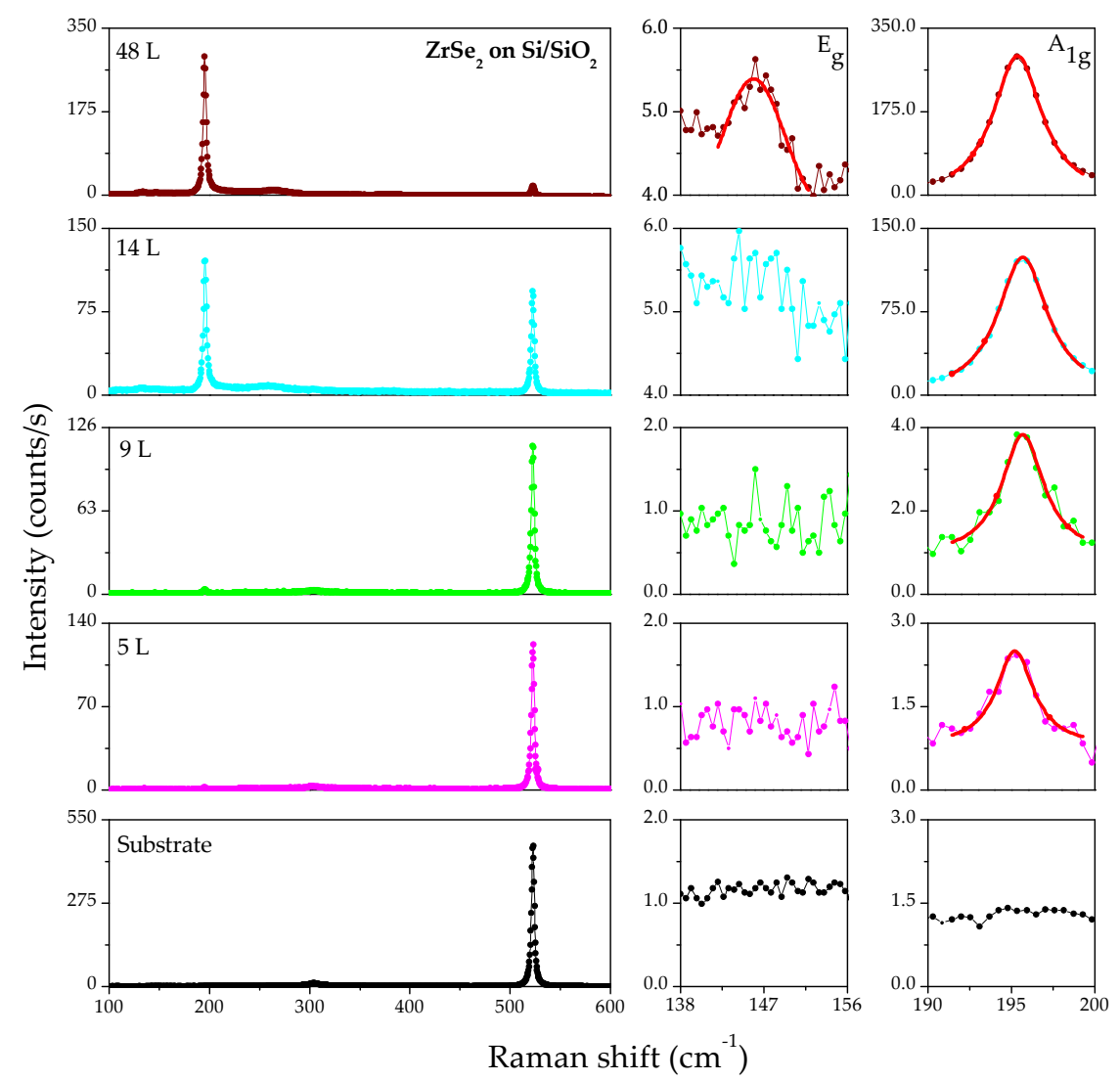

Figure C5. Thickness dependence of the Raman spectra for $\mathrm{ZrSe}_{2}$ on a $\mathrm{Si} / \mathrm{SiO}_{2}$ substrate $(\lambda=638 \mathrm{~nm})$. Broad range spectra as well as zooms in the region of the $\mathrm{A}_{1 \mathrm{~g}}$ and $\mathrm{E}_{\mathrm{g}}$ modes with their corresponding fitting are presented. Fitting results are given in Table C3. 
Table C3. Thickness dependence of the fitted parameters (position, intensity, and FWHM) of the $\mathrm{E}_{\mathrm{g}}$ and $\mathrm{A}_{1 \mathrm{~g}}$ modes obtained from the Raman spectra for $\mathrm{ZrSe}_{2}$ on a $\mathrm{Si} / \mathrm{SiO}_{2}$ substrate $(\lambda=638 \mathrm{~nm})$ presented in Figure C5.

\begin{tabular}{ccccccc}
\hline \multirow{2}{*}{$\begin{array}{c}\text { Thickness } \\
( \pm \mathbf{1} \text { Layer) }\end{array}$} & $\begin{array}{c}\text { Position } \\
\left(\mathbf{c m}^{-\mathbf{1}}\right)\end{array}$ & $\begin{array}{c}\text { Intensity } \\
(\text { Counts/s) }\end{array}$ & $\begin{array}{c}\text { FWHM } \\
\left(\mathbf{c m}^{-\mathbf{1}}\right)\end{array}$ & $\begin{array}{c}\text { Position } \\
\left.\mathbf{( c m}^{-\mathbf{1}}\right)\end{array}$ & $\begin{array}{c}\text { Intensity } \\
(\text { Counts/s) }\end{array}$ & $\begin{array}{c}\text { FWHM } \\
\mathbf{( c m}^{-\mathbf{1}} \mathbf{)}\end{array}$ \\
\hline $48 \mathrm{~L}$ & $145.80 \pm 0.19$ & 5.4 & $3.31 \pm 1.16$ & $195.36 \pm 0.02$ & 291.9 & $3.59 \pm 0.08$ \\
$14 \mathrm{~L}$ & - & - & - & $195.67 \pm 0.02$ & 123.8 & $3.66 \pm 0.09$ \\
$9 \mathrm{~L}$ & - & - & - & $195.68 \pm 0.09$ & 3.8 & $3.1 \pm 0.5$ \\
$5 \mathrm{~L}$ & - & - & - & $195.20 \pm 0.07$ & 2.5 & $2.7 \pm 0.4$ \\
\hline
\end{tabular}

The Raman spectra measured at three different wavelengths (532 nm, $635 \mathrm{~nm}$, and $785 \mathrm{~nm})$ for two thick flakes of $\mathrm{ZrS}_{2}$ and $\mathrm{ZrSe}_{2}$ are shown in Figure C6. Comparing the different spectra for each material (and, in particular, focusing on the intensity of the $A_{1 g}$ mode), we can conclude that an optimized signal can be observed at $532 \mathrm{~nm}$ for $\mathrm{ZrS}_{2}$ and at $638 \mathrm{~nm}$ for $\mathrm{ZrSe}_{2}$.

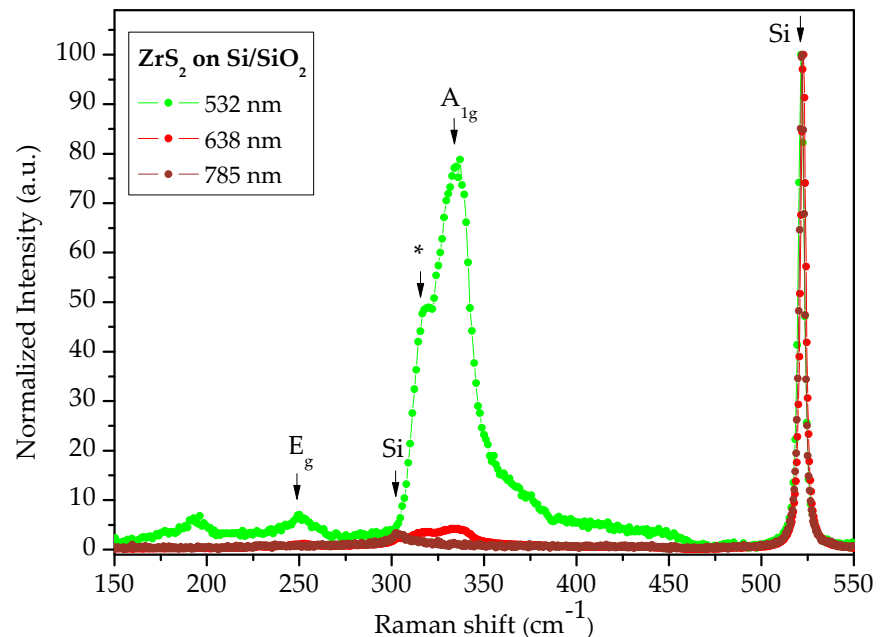

(a)

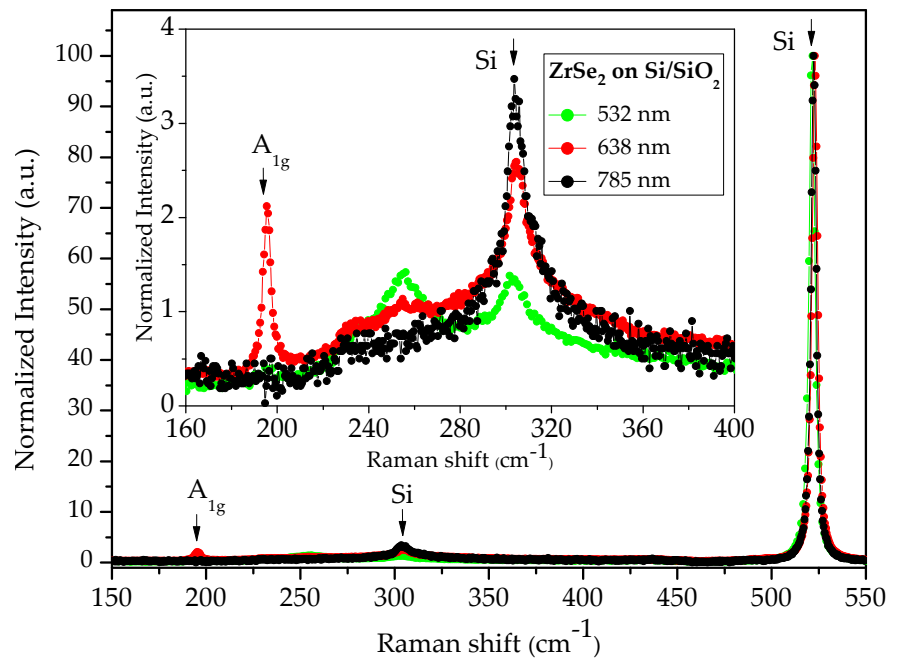

(b)

Figure C6. Raman spectra measured at different wavelengths $(\lambda=532 \mathrm{~nm}, 638 \mathrm{~nm}$, and $785 \mathrm{~nm})$ for (a) $\mathrm{ZrS}_{2}$ and (b) $\mathrm{ZrSe}_{2}$. The intensity has been normalized to the height of the silicon phonon peak. The Raman modes $\mathrm{A}_{1 \mathrm{~g}}$ and $\mathrm{E}_{\mathrm{g}}$ are labeled. For $\mathrm{ZrS}_{2}$, the shoulder marked with "*" is attributed to a broadening of the $\mathrm{A}_{1 \mathrm{~g}}$ peak due to non-harmonic effects. 
In order to compare crystals degradation under ambient conditions, the Raman spectra for bulk crystals of freshly cleaved specimens and uncleaved ones are shown in Figure C7. The intensity has been normalized to the height of the $\mathrm{A}_{1 \mathrm{~g}}$ peak.

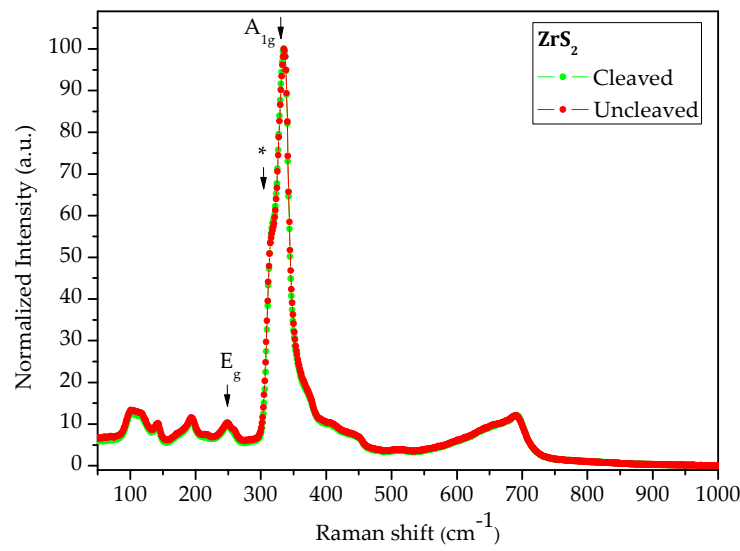

(a)

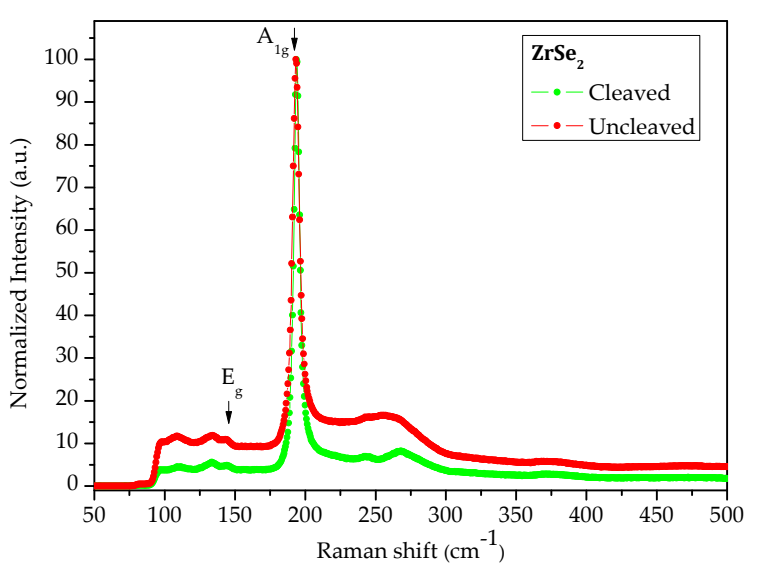

(b)

Figure C7. Raman spectra for freshly cleaved and uncleaved bulk crystals of (a) $\mathrm{ZrS}_{2}(\lambda=532 \mathrm{~nm})$ and (b) $\mathrm{ZrSe}_{2}(\lambda=638 \mathrm{~nm})$. The intensity has been normalized to the height of the $\mathrm{A}_{1 \mathrm{~g}}$ peak. The Raman modes $\mathrm{A}_{1 \mathrm{~g}}$ and $\mathrm{E}_{\mathrm{g}}$ are labeled. For $\mathrm{ZrS}_{2}$, the shoulder marked with "** is attributed to a broadening of the $\mathrm{A}_{1 \mathrm{~g}}$ peak due to non-harmonic effects.

\section{Appendix D. $\mathrm{E}_{\mathrm{g}}$ and $\mathrm{A}_{1 \mathrm{~g}}$ Raman Modes in $\mathrm{ZrX}_{2}$}

The primitive cell of the crystal has three atoms (one formula unit) and thus nine vibrational modes: three of them are acoustic and the other six are optical modes. The decomposition by group theory (at the Gamma point) is (assuming the Wyckoff positions $a$ and $d$ for the $\mathrm{Zr}$ and the S, respectively):

$$
\Gamma=\mathrm{A}_{1 \mathrm{~g}}+\mathrm{E}_{\mathrm{g}}+2 \mathrm{~A}_{2 \mathrm{u}}+2 \mathrm{E}_{\mathrm{u}} .
$$

Half of the modes are even (gerade) and the other half are odd (ungerade) because the space group has a center of symmetry. The A modes are one-dimensional (the atoms move in the $\mathrm{z}$ direction), while the E modes are two-dimensional (the displacement can be, equivalently, in the $\mathrm{x}$ or $\mathrm{y}$ direction). Since the Raman modes are even, the only option is that the $\mathrm{Zr}$ atom remains at rest, while the two $S$ atoms move in opposite directions. There is no dipole moment, but a change in the Raman polarizability. In the case of the $A_{1 g}$ mode, there is a plane of $S$ atoms against the other (like a stretching mode) while in the case of the $\mathrm{E}_{\mathrm{g}}$ mode, the $\mathrm{S}$ planes slide one against the other (see Figure 1c). Thus, the first mode must have a substantially higher frequency as compared to the second mode. In fact, as already stated in the literature [33], the $E_{g}$ mode has a frequency of $251 \mathrm{~cm}^{-1}$, while $A_{1 g}$ has a frequency of $333 \mathrm{~cm}^{-1}$. Now, following a simple rule, the frequency can be taken as:

$$
\omega=(\mathrm{k} / \mathrm{M})^{1 / 2},
$$

where $\mathrm{k}$ is the spring constant $[\mathrm{N} / \mathrm{m}]$. In the case of the Raman allowed modes, the mass $(\mathrm{M})$ that is entered in this expression is the reduced mass of the two $S$ atoms vibrating one against the other. However, this is not the case with the IR modes since, in that case, the $\mathrm{Zr}$ atom moves against two $\mathrm{S}$ atoms and creates a dipole. In that case the reduced mass, $\mu$, must be calculated as:

$$
\mu^{-1}=\left(2 \mathrm{M}_{\mathrm{S}}\right)^{-1}+\left(\mathrm{M}_{\mathrm{Zr}}\right)^{-1} .
$$

Equation (3) gives a much smaller value for the mass, which means a much higher frequency. Actually, the IR spectra of several transition metal sulfides are in agreement with the previous tendency. 
In the case of $\mathrm{ZrS}_{2}$, it is around $500 \mathrm{~cm}^{-1}$ [34]. Thus, the high broadening of the $\mathrm{A}_{1 \mathrm{~g}}$ peak in $\mathrm{ZrS}_{2}$ seems to be unrelated to the appearance of IR modes (all polar modes have TO and LO). The clearest case is the comparison with its parent compound, $\mathrm{ZrSe}_{2}$. The $\mathrm{A}_{1 \mathrm{~g}}$ mode in that case is a sharp peak.

On the contrary, there are several factors contributing to the phonon line width or broadening. The most important one is the anharmonicity, the second is the isotopic disorder, and the third is the electron-phonon interaction. At room temperature, anharmonicity is usually the most important one. $\mathrm{Ab}$ initio calculations in the lattice dynamics of $\mathrm{ZrSe}_{2}$ and $\mathrm{ZrS}_{2}$ reveal that there is no LO-TO splitting. There is a huge density of states (a very flat dispersion, covering the entire Brillouin zone) around the $\mathrm{A}_{1 \mathrm{~g}}$ mode in $\mathrm{ZrS}_{2}$, while in the case of $\mathrm{ZrSe}_{2}$ the dispersion is not so flat [35]. Thus, the reason for the broadening of the $A_{1 g}$ peak can be attributed to anharmonicity. The phonon can emit acoustic phonons (with practically no energy), giving rise to this huge broadening.

\section{Appendix E. Discussion of Flake Degradation}

During experiments, special care had to be taken in order to avoid and minimize flake degradation. Indeed, the use of a high laser power density and a long exposition time during Raman measurements has been found to have dramatic effects on the flakes surface. This can be seen in Figure E1, which shows an AFM tapping image of a $\mathrm{ZrS}_{2}$ flake after exposure to the laser for some minutes. A hole of about $1.9 \mathrm{~nm}$ produced by the laser over the flake surface is clearly visible.

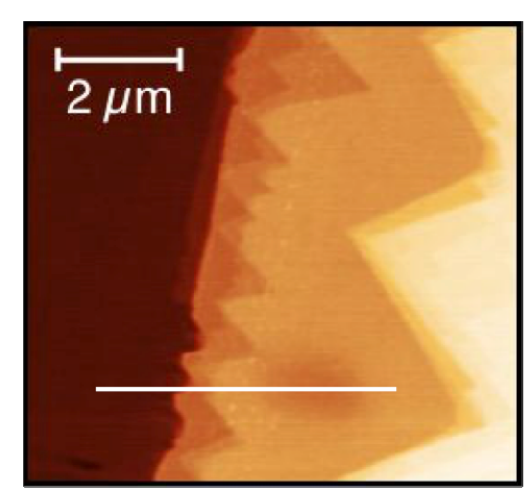

(a)

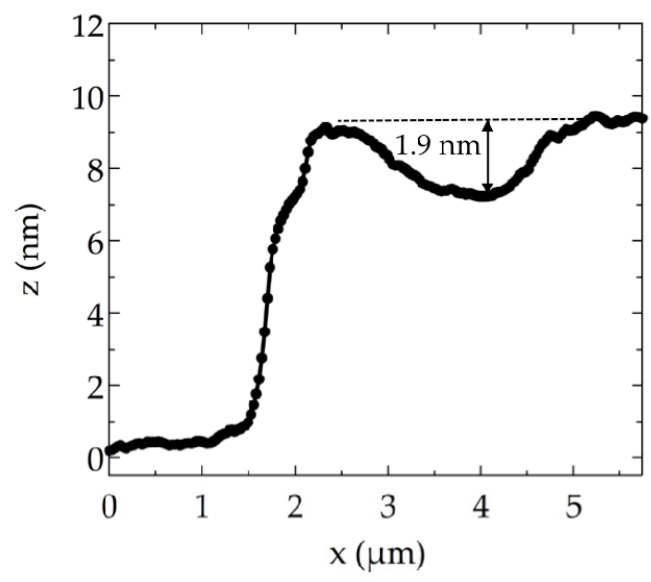

(b)

Figure E1. (a) AFM tapping image and (b) height profile of a $\mathrm{ZrS}_{2}$ flake after Raman measurement. During the measurement the flake has been exposed to a laser spot (power density of $5.25 \mathrm{~mW} / \mu \mathrm{m}^{2}$ ) for some minutes, causing a hole of about $1.9 \mathrm{~nm}$ on the flake surface.

In order to avoid this inconvenience, laser power density and exposition time have been optimized to avoid flake surface modification after measurement. An AFM tapping image of a flake before and after Raman measurement with these optimized parameters is shown in Figure E2 and no difference can be appreciated on the flake surface due to the laser exposure.

Nevertheless, an increase in flake thickness can be observed in the second measurement. We also measured it after 10 days but no further increase on flake thickness was observed. This thickness increasing could be a hint of flake oxidation or just due to an increasing of the "dead layer" as a consequence of sample exposition to ambient humidity.

Another hint suggesting the possible flake degradation due to ambient oxidation is represented by the fact that, especially for $\mathrm{ZrSe}_{2}$, no Raman signal could be observed on the thin flakes after sample exposition to the air for some days. Moreover, the surface of $\mathrm{ZrSe}_{2}$ flakes appears to be quite damaged even after a short exposure to the air (one day), as shown in Figure E3. 
By these observations, and taking into account previously reported results in the literature that show how the surface of $\mathrm{ZrX}_{2}$ bulk crystals passivates (amorphous oxides) [37,38], we are led to think that the oxidation process could play an important role in these systems (oxidation effects are expected to be much more dramatic in thinner flakes). Thus we suggest that further research should be performed in encapsulated samples or under inert gas conditions to exclude this problem.

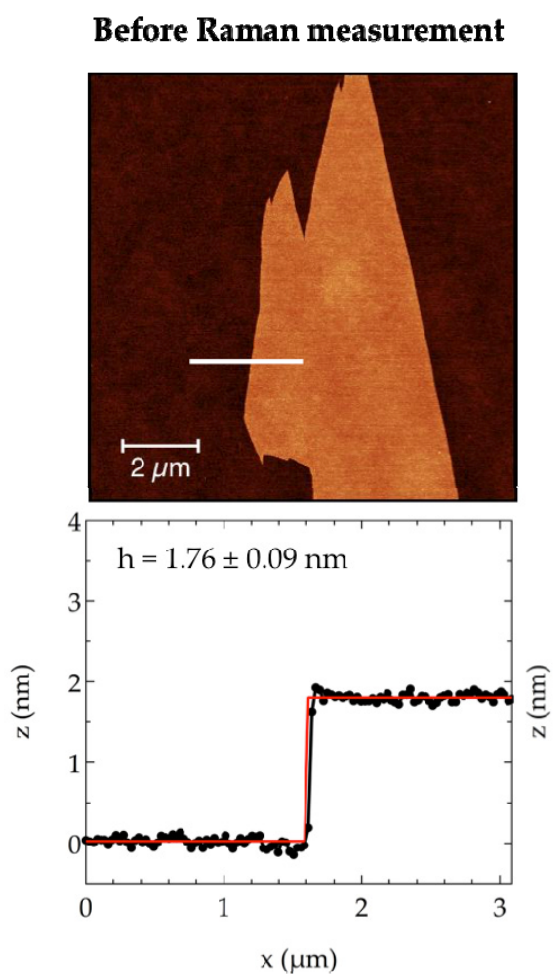

(a)

\section{After Raman measurement}
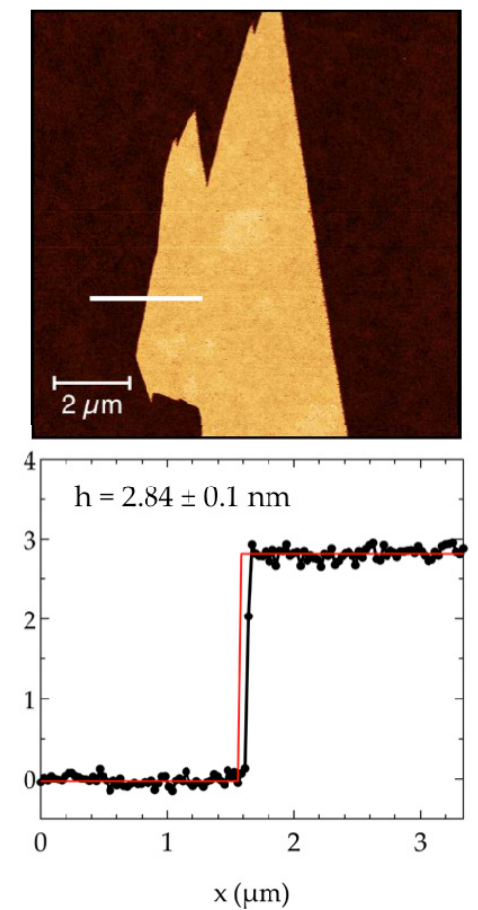

(b)

Figure E2. AFM tapping images (top row) and respective height profiles (bottom row) for a thin $\mathrm{ZrS}_{2}$ flake before (a) and after (b) Raman measurement. No change can be observed in the flake surface before and after Raman measurement since the laser power density and exposition time have been optimized to avoid any damage to the flake surface. However, flake thickness is higher after Raman measurement. This is due to the longer exposure of the sample to air after the measurement. The increase could be explained by flake oxidation or an increase of the "dead layer" due to ambient humidity.

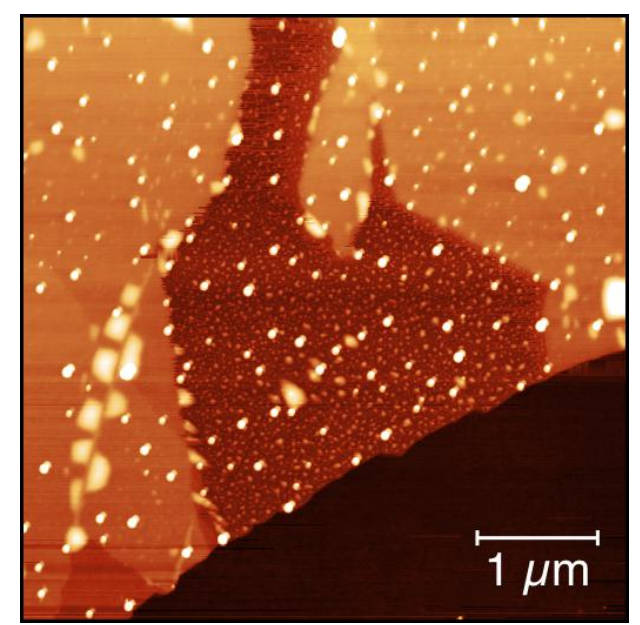

Figure E3. AFM tapping image of a $\mathrm{ZrSe}_{2}$ flake after one day of sample exposure to the air. 


\section{References}

1. Bhimanapati, G.R.; Lin, Z.; Meunier, V.; Jung, Y.; Cha, J.; Das, S.; Xiao, D.; Son, Y.; Strano, M.S.; Cooper, V.R.; et al. Recent Advances in Two-Dimensional Materials beyond Graphene. ACS Nano 2015, 9, 11509-11539. [CrossRef] [PubMed]

2. Wilson, J.A.; Yoffe, A.D. The transition metal dichalcogenides discussion and interpretation of the observed optical, electrical and structural properties. Adv. Phys. 1969, 18, 193-335. [CrossRef]

3. Andrei, E.Y.; Li, G.; Du, X. Electronic properties of graphene: A perspective from scanning tunneling microscopy and magnetotransport. Rep. Prog. Phys. 2012, 75, 56501. [CrossRef] [PubMed]

4. Peng, B.; Ang, P.K.; Loh, K.P. Two-dimensional dichalcogenides for light-harvesting applications. Nano Today 2015, 10, 128-137. [CrossRef]

5. Wang, Q.H.; Kalantar-Zadeh, K.; Kis, A.; Coleman, J.N.; Strano, M.S. Electronics and optoelectronics of two-dimensional transition metal dichalcogenides. Nat. Nanotechnol. 2012, 7, 699-712. [CrossRef] [PubMed]

6. Frindt, R.F. Superconductivity in ultrathin $\mathrm{NbSe}_{2}$ layers. Phys. Rev. Lett. 1972, 28, 299-301. [CrossRef]

7. El-Bana, M.S.; Wolverson, D.; Russo, S.; Balakrishnan, G.; Paul, D.M.; Bending, S.J. Superconductivity in two-dimensional $\mathrm{NbSe}_{2}$ field effect transistors. Supercond. Sci. Technol. 2013, 26, 125020. [CrossRef]

8. Ugeda, M.M.; Bradley, A.J.; Zhang, Y.; Onishi, S.; Chen, Y.; Ruan, W.; Ojeda-Aristizabal, C.; Ryu, H.; Edmonds, M.T.; Tsai, H.; et al. Characterization of collective ground states in single-layer $\mathrm{NbSe}_{2}$. Nat. Phys. 2015, 12, 92-97. [CrossRef]

9. Navarro-Moratalla, E.; Island, J.O.; Mañas-Valero, S.; Pinilla-Cienfuegos, E.; Castellanos-Gomez, A.; Quereda, J.; Rubio-Bollinger, G.; Chirolli, L.; Silva-Guillén, J.A.; Agraï, N.; et al. Enhanced superconductivity in atomically thin $\mathrm{TaS}_{2}$. Nat. Commun. 2016, 7, 11043. [CrossRef] [PubMed]

10. Li, L.J.; O’Farrell, E.C.T.; Loh, K.P.; Eda, G.; Özyilmaz, B.; Castro Neto, A.H. Controlling many-body states by the electric-field effect in a two-dimensional material. Nature 2015. [CrossRef] [PubMed]

11. Xu, K.; Wang, Z.; Wang, F.; Huang, Y.; Wang, F.; Yin, L.; Jiang, C.; He, J. Ultrasensitive Phototransistors Based on Few-Layered $\mathrm{HfS}_{2}$. Adv. Mater. 2015, 27, 7881-7887. [CrossRef] [PubMed]

12. Kanazawa, T.; Amemiya, T.; Ishikawa, A.; Upadhyaya, V.; Tsuruta, K.; Tanaka, T.; Miyamoto, Y. Few-layer HfS2 transistors. Sci. Rep. 2016, 6, 22277. [CrossRef] [PubMed]

13. Yue, R.; Barton, A.T.; Zhu, H.; Azcatl, A.; Pena, L.F.; Wang, J.; Peng, X.; Lu, N.; Cheng, L.; Addou, R.; et al. $\mathrm{HfSe}_{2}$ Thin Films: 2D Transition Metal Dichalcogenides Grown by Molecular Beam Epitaxy. ACS Nano 2015, 9, 474-480. [CrossRef] [PubMed]

14. Zhang, W.; Huang, Z.; Zhang, W.; Li, Y. Two-dimensional semiconductors with possible high room temperature mobility. Nano Res. 2014, 7, 1731-1737. [CrossRef]

15. Guo, H.; Lu, N.; Wang, L. Tuning Electronic and Magnetic Properties of Early Transition Metal Dichalcogenides via Tensile Strain. J. Phys. Chem. C 2014, 118, 7242-7249. [CrossRef]

16. Li, Y.; Kang, J.; Li, J. Indirect-to-direct band gap transition of the $\mathrm{ZrS}_{2}$ monolayer by strain: First-principles calculations. RSC Adv. 2014, 4, 7396. [CrossRef]

17. Kumar, A.; He, H.; Pandey, R.; Ahluwalia, P.K.; Tankeshwar, K. Semiconductor-to-metal phase transition in monolayer $\mathrm{ZrS}_{2}$ : GGA+U study. In Proceedings of the AIP Conference, Tamilnadu, India, 16-20 December 2014; p. 90016.

18. Jeong, S.; Yoo, D.; Ahn, M.; Miró, P.; Heine, T.; Cheon, J. Tandem intercalation strategy for single-layer nanosheets as an effective alternative to conventional exfoliation processes. Nat. Commun. 2015, 6, 5763. [CrossRef] [PubMed]

19. Jang, J.T.; Jeong, S.; Seo, J.W.; Kim, M.C.; Sim, E.; Oh, Y.; Nam, S.; Park, B.; Cheon, J. Ultrathin zirconium disulfide nanodiscs. J. Am. Chem. Soc. 2011, 133, 7636-7639. [CrossRef] [PubMed]

20. Zhang, M.; Zhu, Y.; Wang, X.; Feng, Q.; Qiao, S.; Wen, W.; Chen, Y.; Cui, M.; Zhang, J.; Cai, C.; et al. Controlled Synthesis of $\mathrm{ZrS}_{2}$ Monolayer and Few-layers on Hexagonal Boron Nitride. J. Am. Chem. Soc. 2015, 137, 7051-7054. [CrossRef] [PubMed]

21. Li, L.; Fang, X.; Zhai, T.; Liao, M.; Gautam, U.K.; Wu, X.; Koide, Y.; Bando, Y.; Golberg, D. Electrical Transport and High-Performance Photoconductivity in Individual ZrS2 Nanobelts. Adv. Mater. 2010, 22, 4151-4156. [CrossRef] [PubMed]

22. Wang, X.; Huang, L.; Jiang, X.-W.; Li, Y.; Wei, Z.; Li, J. Large scale $\mathrm{ZrS}_{2}$ atomically thin layers. J. Mater. Chem. C 2016, 4, 3143-3148. [CrossRef] 
23. Tsipas, P.; Tsoutsou, D.; Marquez-Velasco, J.; Aretouli, K.E.; Xenogiannopoulou, E.; Vassalou, E.; Kordas, G.; Dimoulas, A. Epitaxial $\mathrm{ZrSe}_{2} / \mathrm{MoSe}_{2}$ semiconductor v.d. Waals heterostructures on wide band gap AlN substrates. Microelectron. Eng. 2015, 147, 269-272. [CrossRef]

24. Ferrari, A.; Basko, D. Raman spectroscopy as a versatile tool for studying the properties of graphene. Nat. Nanotechnol. 2013, 8, 235-246. [CrossRef] [PubMed]

25. Chen, Y.; Dumcenco, D.O.; Zhu, Y.; Zhang, X.; Mao, N.; Feng, Q.; Zhang, M.; Zhang, J.; Tan, P.-H.; Huang, Y.-S.; et al. Composition-dependent Raman modes of $\mathrm{Mo}(1-\mathrm{x}) \mathrm{W}(\mathrm{x}) \mathrm{S}_{2}$ monolayer alloys. Nanoscale 2014, 6, 2833-2839. [CrossRef] [PubMed]

26. Lee, J.-U.; Kim, K.; Han, S.; Ryu, G.H.; Lee, Z.; Cheong, H. Raman Signatures of Polytypism in Molybdenum Disulfide. ACS Nano 2016, 10, 1948-1953. [CrossRef] [PubMed]

27. Li, H.; Zhang, Q.; Yap, C.C.R.; Tay, B.K.; Edwin, T.H.T.; Olivier, A.; Baillargeat, D. From Bulk to Monolayer $\mathrm{MoS}_{2}$ : Evolution of Raman Scattering. Adv. Funct. Mater. 2012, 22, 1385-1390. [CrossRef]

28. Rice, C.; Young, R.J.; Zan, R.; Bangert, U.; Wolverson, D.; Georgiou, T.; Jalil, R.; Novoselov, K.S. Raman-scattering measurements and first-principles calculations of strain-induced phonon shifts in monolayer $\mathrm{MoS}_{2}$. Phys. Rev. B 2013, 87, 81307. [CrossRef]

29. Eckmann, A.; Felten, A.; Mishchenko, A.; Britnell, L.; Krupke, R.; Novoselov, K.S.; Casiraghi, C. Probing the nature of defects in graphene by Raman spectroscopy. Nano Lett. 2012, 12, 3925-3930. [CrossRef] [PubMed]

30. Whitehouse, C.R.; Balchin, A.A. Non-stoichiometry in $\mathrm{ZrS}_{2}$ and $\mathrm{ZrSe}_{2}$. Phys. Stat. Solidi 1978, 47, $173-176$. [CrossRef]

31. Klipstein, P.C.; Pereira, C.M.; Friend, R.H. Transport and Raman studies of the group IV layered compounds and their lithium intercalates: $\mathrm{LixTiS}_{2}, \mathrm{LixTiSe}_{2}, \mathrm{LixZrS}_{2}, \mathrm{LixZrSe}_{2}, \mathrm{LixHfS}_{2}$ and $\mathrm{LixHfSe}_{2}$. Philos. Mag. Part B 1987, 56, 531-559. [CrossRef]

32. Novoselov, K.S.; Geim, A.K.; Morozov, S.V.; Jiang, D.; Zhang, Y.; Dubonos, S.V.; Grigorieva, I.V.; Firsov, A.A. Electric field effect in atomically thin carbon films. Science 2004, 306, 666-669. [CrossRef] [PubMed]

33. Roubi, L.; Carlone, C. Resonance Raman spectrum of $\mathrm{HfS}_{2}$ and $\mathrm{ZrS}_{2}$. Phys. Rev. B 1988, 37, 6808-6812. [CrossRef]

34. Liang, B.; Andrews, L. Infrared Spectra and Density Functional Theory Calculations of Group 4 Transition Metal Sulfides. J. Phys. Chem. A 2002, 106, 6295-6301. [CrossRef]

35. Yumnam, G.; Pandey, T.; Singh, A.K. High temperature thermoelectric properties of Zr and Hf based transition metal dichalcogenides: A first principles study. J. Chem. Phys. 2015, 143, 234704. [CrossRef] [PubMed]

36. Temple, P.A.; Hathaway, C.E. Multiphonon Raman Spectrum of Silicon. Phys. Rev. B 1973, 7, 3685-3697. [CrossRef]

37. McTaggart, F.K. The sulphides, Selenides, and Tellurides of Titanium, Zirconium, Hafnium, and Thorium. III. Electrical properties. Aust. J. Chem. 1958, 11, 471-480. [CrossRef]

38. Bear, J.; McTaggart, F. The sulphides, Selenides, and Tellurides of Titanium, Zirconium, Hafnium, and Thorium. II. Chemical properties. Aust. J. Chem. 1958, 11, 458-470. [CrossRef]

39. Chae, S.H.; Jin, Y.; Kim, T.S.; Chung, D.S.; Na, H.; Nam, H.; Kim, H.; Perello, D.J.; Jeong, H.Y.; Ly, T.H.; et al. Oxidation Effect in Octahedral Hafnium Disulfide Thin Film. ACS Nano 2016, 10, 1309-1316. [CrossRef] [PubMed]

40. Cao, Y.; Mishchenko, A.; Yu, G.L.; Khestanova, E.; Rooney, A.P.; Prestat, E.; Kretinin, A.V.; Blake, P.; Shalom, M.B.; Woods, C.; et al. Quality Heterostructures from Two-Dimensional Crystals Unstable in Air by Their Assembly in Inert Atmosphere. Nano Lett. 2015, 15, 4914-4921. [CrossRef] [PubMed]

41. Greenaway, D.L.; Nitsche, R. Preparation and optical properties of group IV-VI2 chalcogenides having the $\mathrm{CdI}_{2}$ structure. J. Phys. Chem. Solids 1965, 26, 1445-1458. [CrossRef]

(C) 2016 by the authors; licensee MDPI, Basel, Switzerland. This article is an open access article distributed under the terms and conditions of the Creative Commons Attribution (CC-BY) license (http://creativecommons.org/licenses/by/4.0/). 